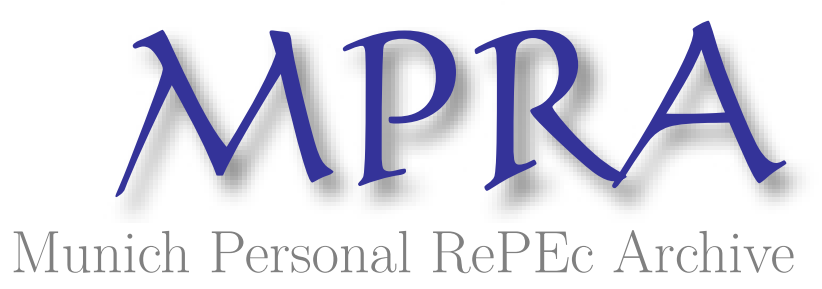

The Impacts of Trade Liberalization on Informal Labor Markets: A Theoretical and Empirical Evaluation of the Brazilian Case.

Paz, Lourenco

Syracuse University

7 May 2012

Online at https://mpra.ub.uni-muenchen.de/44928/

MPRA Paper No. 44928, posted 10 Mar 2013 16:58 UTC 


\title{
The Impacts of Trade Liberalization on Informal Labor Markets: A Theoretical and Empirical Evaluation of the Brazilian Case.*
}

\author{
Lourenço S. Paz \\ Department of Economics \\ 110 Eggers Hall \\ Syracuse University \\ Syracuse, NY 13244 USA
}

Phone: 1(315)443-5874, Fax: 1(315)443-3717

lspaz@maxwell.syr.edu

\begin{abstract}
Following trade liberalization, several developing countries experienced a sharp increase in the share of informal manufacturing employment. In this paper, I examine the impacts of trade liberalization on the labor markets of a small open economy, in an environment in which tariffs affect firms' payroll tax compliance decisions. I demonstrate that a reduction in domestic import tariffs reduces the average formal wage and show that the direction of the effect on the share of informal employment depends on the initial labor market conditions. A cut in trading partner import tariffs decreases the share of domestic informal employment and increases the average formal wage. I confirm the model's principal findings empirically, using data from the 1989-2001 Brazilian trade liberalization episode. I find the results robust to endogeneity and self-selection concerns, which are addressed, respectively, using instrumental variable and switching regression approaches.
\end{abstract}

Keywords: Brazil, informal labor markets, payroll tax, trade liberalization.

JEL Codes: F1, H2, O17.

${ }^{*}$ This paper is a merged and updated version of the papers 'The effect of trade liberalization on payroll tax evasion and labor informality' and 'The impacts of trade liberalization on informal labor markets: an evaluation of the Brazilian case.' 


\section{Introduction}

The coexistence of formal jobs with informal ones that do not meet basic legal requirements not only is a common worldwide phenomenon but an increasingly important one (see, for example, Schneider and Enste, 2000). Indeed, in many developing countries, a substantive share of the workforce is employed informally — for instance, in Brazil, China, and Colombia in excess of $30 \%$ of all employment can be classified as informal. ${ }^{1}$ For Brazil and Argentina, Neri (2001) and Pratap and Quintin (2006) provide empirical evidence that suggests the principal economic distinction between formal and informal jobs centers on firms' payroll tax compliance decisions. Thus, although most employers comply with myriad other labor market regulations, there is a sharp divide between those that do and those that do not pay payroll taxes.

Given the demarcation just described between the two job types, the extent of informal employment clearly has important ramifications for total government tax revenues. Indeed, Rodrik (1992) suggests that trade policy-government revenue channel is a key determinant of whether a country subsequently engages in trade liberalization. Hence, the potentially potent effects of a country's choice of trade policy instruments on its domestic formal and informal labor markets can magnify the relevance of Rodrik's (1992) remark. Furthermore, many observers regard informal employment as synonymous with inferior employment-see, for example the recent World Trade Organization-International Labour Organization report (Bacchetta, Ernst, and Bustamante, 2009). These latter concerns even have shaped the form of recent trade agreements reached by the United States with its Latin American trading partners, since many of them now require the counterparty to follow provisions concerning labor regulations and their enforcement. ${ }^{2}$

In view of the remarks just made, it is of considerable interest and potentially of great concern for policy makers that a recent and growing body of evidence points to the fact that trade liberalization episodes (in particular, those carried out by the economies of Latin America) are associated with a substantial increase in the share of informal workers employed in the manufacturing sectorsee Perry et al. (2007). This phenomenon is illustrated in Figure 1 for Brazil. Notice that in the

\footnotetext{
${ }^{1}$ As found by Goldberg and Pavcnik (2003) for Brazil and Colombia, and by Mao, Zhang, and Zhao (2012) for urban China.

${ }^{2}$ In particular, the 2006 United States trade agreement with Peru includes strengthening and broadening labor inspectors' powers and increases the level of fines (see Office of the United States Trade Representative, 2007). Similarly, the 2006 United States trade agreement with Colombia featured the creation of a Labor ministry and a substantial increase in the number of labor inspectors (see Office of the United States Trade Representative, 2011).
} 
aftermath of the trade liberalization process, which began in 1990, the share of informal workers employed in the Brazilian manufacturing sector increased from $12 \%$ to $20.4 \%$. Most important, notice too that, over the same period, the share of informal workers employed in the service sector remained stable. Another significant empirical feature associated with each of these trade liberalization episodes - as documented by Hanson and Harrison (1999) for Mexico and by Pavcnik et al. (2004) for Brazil - is the absence of any substantive change in the employment shares in the manufacturing industries. In view of these findings, it follows that, in response to trade shocks, intraindustry changes in the share of informal employment (hereafter, the informality share) might constitute a potent labor adjustment margin and so warrant careful investigation.

This latter observation motivates this paper. In it, I construct a theoretical model that is designed to capture the impact of trade policy changes in a country's formal and informal labor markets. More specifically, I consider an environment with heterogeneous firms, in which each firm's optimal payroll tax compliance decisions (and so its formal-informal employment choices) are endogenous. To explore the ramifications of changes in the trade environment on the informality share, I embed this payroll tax compliance decision in a small open economy (SOE) version of Davis and Harrigan's (2011) Good Jobs, Bad Jobs framework. The model then is implemented empirically using data from the 1989-2001 Brazilian trade liberalization.

The principal goals of the theoretical model are to uncover the effects of changes in import tariffs - domestic and those of the country's trading partners - on the equilibrium levels of the industry-level share of informal employment, the average formal wage, and the average informal wage. In contrast to the previous studies, a notable feature of my SOE general equilibrium framework is that it is rich enough to allow for countries of different sizes and to encompass both differential timing and magnitudes of policy changes. I find that a decrease in domestic import tariffs lowers the average formal wage but has a (genuine) ambiguous effect on the employment share of informal workers. More specifically, I show that the predicted sign of the domestic tariffinformality employment share nexus hinges on the initial (i.e., pre-reform) labor market conditions. A reduction in the country's trading partner's import tariffs decreases the informality share but increases the average formal wage; however, I show that the effect on the average informal wage is ambiguous.

As discussed later, the available empirical evidence concerning the magnitude and direction of 
the effect of changes in the trade environment on informal employment is far from conclusive. In this light, my paper further contributes to this important and growing body of literature not only by providing new estimates but also by introducing several important methodological improvements. First, consonant with Almeida and Carneiro's (2012) recent findings, I show that the enforcement of labor regulations is a key determinant of the extent of informal employment. The extant literature, however, has largely failed to address this important concern. In this paper, I take steps to address it by carefully controlling for spatial and temporal heterogeneity in enforcement efforts. Furthermore, I instrument for Brazilian import tariffs to address possible simultaneity concerns regarding the joint determination of import tariff levels and payroll tax enforcement efforts. Finally, to obtain consistent estimates of the trade policy effects on the average levels of formal and informal wages, I employ a switching regressions technique. This helps overcome a ubiquitous problem in the literature of failing to control the simultaneous determination of wages and formality employment status, thereby addressing the issue of worker self-selection between formal and informal work.

I evaluate the model's testable predictions using Brazilian data, which have several noteworthy merits. First, the definition of labor informality used in the theoretical model is directly observable in Brazilian household surveys, since they include a specific question concerning employer payroll tax compliance. This potentially represents a significant improvement in the literature, which has been hampered by the lack of a uniform definition of labor informality. As a result, it has been difficult not only to link the theory seamlessly with the empirics but also to draw robust comparisons across different studies. Second, Brazil experienced economically significant changes in its trade environment. Specifically, as a result of the changes in trade policies that occurred during the 1990s, Brazil and its trading partners witnessed sharp decreases in their import tariffs. The changes in the trade environment led to changes in Brazilian import and export levels in excess of $60 \%$. Third, Brazil's labor institutions and its labor market regulations remained stable throughout this period of trade liberalization. This is helpful in identifying the trade-environment-labor-market nexus, which is the central concern of this paper. In contrast, several other countries, including Chile, implemented substantial labor market reforms over the same period they were engaging in trade liberalization.

My empirical results provide evidence that the effects of a reduction in import tariffs by Brazil's principal trade partners are to raise the Brazilian industry-level average formal wage and decrease 
the share of informal employment. Alternatively, a reduction in Brazilian import tariffs has precisely the opposite effect. This former result is potentially of considerable policy importance because it suggests increased access to large markets, such as the United States, offers a potent market-based remedy for improving labor conditions in developing countries. For the average informal wage, the empirical results are often not statistically significant and coefficients switch signs depending on which identification strategy is used. In addition, I show the magnitudes of the tariff effects on the average formal and average informal wage is inversely related to the likelihood of the worker having an informal job. Thus, although multilateral trade liberalization may reduce informality and increase the average formal wage, the empirical results suggest that the benefits arising from trade liberalization differ according to the workers characteristics. My paper findings still hold after several robustness checks, including a falsification test designed to test whether pre-existing trends in the data are driving the results.

This paper is related to a growing body of work that examines the nexus between the share of informal employment and changes in the international trade environment. For example, Acosta and Montes-Rojas (2010) conduct an empirical investigation using Argentinean data, and find that a decrease in domestic tariffs substantially increases the industry-level informality share in manufacturing. Alemán-Castilla (2006) find a decline in U.S. tariffs reduces the informality share in the Mexican tradable sector, but a decrease in Mexican import tariffs has no effect on informality. Goldberg and Pavcnik (2003), who use Brazilian and Colombian data, find that a decrease in import tariffs slightly increased the informality share in Colombia but had no effect in Brazil. MenezesFilho and Muendler (2011), who also use Brazilian data, examine the effect of import tariffs on the likelihood a worker will switch form formal manufacturing employment to informal work. Their principal finding, however, is that tariffs have no effect on this transition probability. Bosch, Goni, and Maloney (2007) also investigate the behavior of labor informality in Brazil; however, they find that changes in the international trade regime have little effect on the changes in the informality share observed over the period.

Clearly, the results of the extant literature are mixed. Nevertheless, using the theoretical model developed in this paper it becomes possible to rationalize some of these disparities. Moreover, as we shall see, the methodological concerns raised in this paper also can help to explain the source of the mixed results found in the literature for Brazilian data. This is so because one of my empirical 
specifications that do not include any of my methodological improvements finds results that are in line with the mixed results provided in the literature.

The remainder of the paper is organized as follows. Section 2 presents the salient stylized facts concerning informality and introduce the theoretical model and its testable predictions. In section 3, I discuss the empirical specifications to be estimated. The data used is described in section 4 . Section 5 presents the empirical results and several robustness checks. I offer some conclusions in section 6 .

\section{Informality Stylized Facts and Theoretical Model}

This section begins with a brief presentation of stylized facts concerning the informal labor markets that comprise the building blocks of my theoretical model. Next, my theoretical model and its testable predictions are described and discussed vis-à-vis the existing literature.

\subsection{Informality Stylized Facts and Modeling Strategy}

A large strand of the literature defines informality as being based solely on compliance with regulations. ${ }^{3}$ For example, Schneider and Enste (2000, p. 79) define the informal economy as the "legal value-added creating activities which are not taxed or registered and where the largest part can be classified as clandestine labor, which means that unpaid or 'pure' household production, voluntary nonprofit (social) services and criminal activities are excluded." According to Portes et al. (1989, p.30), "the best-known economic effect of the informalization process is to reduce the costs of labor substantially." Among these labor costs, the payroll tax is the largest component, typically accounting for 15 to $30 \%$ of the wage. Furthermore, whether firms comply with the payroll tax is arguably the root distinction between formal and informal jobs in Argentina (Pratap and Quintin, 2006) and Brazil (Neri, 2002). Thus, I define an informal job as an employment relationship in which the employer does not comply with the payroll tax. ${ }^{4}$ Using this definition of informality, I present four important stylized facts.

\footnotetext{
${ }^{3}$ In contrast, the International Labor Organization (ILO, 2001) defines informal jobs as those offered by firms with five or less workers regardless of compliance with labor regulations.

${ }^{4}$ This tax compliance characterization of informality is also present in the Public Finance literature, see Keen (2008) and Davies and Paz (2011), among others.
} 
Fact 1: Informality is pervasive across manufacturing industries.

As displayed in Table 1, informality is present with different intensities in every manufacturing industry in Brazil. Moreover, Goldberg and Pavcnik (2003) found similar results for Colombia, and Alemán-Castilla (2006) for Mexico. This means that informality is not an industry-specific phenomenon, and in particular we can see that the informality share increased in every manufacturing industry.

Fact 2: Most of the informal share variation occurred within manufacturing industries.

I find that $85 \%$ of the informality share variation is within manufacturing industries during the 1989-2001 Brazilian trade liberalization. Goldberg and Pavcnik (2003) find that almost all variation in informality during trade liberalization in Colombia is also within-industry. So, the increase in informality in the manufacturing sector is not driven by between industry changes, as would happen in a Ricardian or Heckscher-Ohlin framework.

Fact 3: Small firms are more likely to hire informal workers.

Pratap and Quintin (2006) find for Argentina that informal jobs are more prominent among firms employing few workers. Neri (2002) finds similar results for Brazil. Although informal workers are more likely to be found in small establishments in Brazil, Table 2 demonstrates that some small establishments utilize formal workers. Additionally, we find that larger establishments are more likely to employ formal workers. According to Ellery and Gomes (2007), large establishments are also responsible for almost all Brazilian manufacturing exports. This suggests that informal workers are not used for producing exported goods.

Fact 4: Trade liberalization leads to labor reallocation across firms of different sizes.

McCaig and Pavcnik (2012) using Vietnam household rotating-panel data find evidence that trade liberalization (both unilateral and multilateral) leads to a reallocation of labor from small to large firms. This means that trade policies affect firms differently according to their size, in particular small firms become smaller and large firms get larger.

In the literature, the first and second stylized facts are consistent with two modeling strategies. The first is a representative firm that employs people by offering formal and informal labor 
contracts, such as the model constructed by Goldberg and Pavcnik (2003). The second is a model of within-industry firm heterogeneity, in which some firms hire formal workers while others hire informal workers, as in Alemán-Castilla (2006). However, the representative firm framework cannot accommodate the third and fourth stylized facts. Both of which suggest that trade-induced reallocation of employment across firms of different sizes would lead to within-industry changes in the share of informal workers because firms of different sizes differ in their propensity to employ informal workers. Nonetheless, the class of heterogeneous firm models à la Melitz (2003) can generate these four stylized facts, as I explain next.

In my model, firms will choose whether to comply or not with payroll taxes depending on their expected profits, because tax evasion leads to a fine if caught. Following the Davis and Harrigan (2011) framework, firms are heterogeneous in their productivity and wages paid, thus there exist firms that have the same level of productivity yet pay different wages. ${ }^{5}$ This is crucial to generate the third stylized fact in which some small firms hire formal workers.

\subsection{The Theoretical Model}

I first describe the basic environment of my theoretical model. Next, I lay out the workers preferences and the firms' technology. Then, I define the two labor contracts available in the economy: formal and informal. Accordingly, the heterogeneous firms' profit maximization problem can now be formulated, which provides the choices of labor contract offered and markets served. By solving for the general equilibrium, I am able to partition the firms according to their optimal choices of labor contracts and markets served. Finally, I conduct comparative statics to obtain predictions regarding the effect of trade policies on the share of informal workers and average formal and informal wages, which will be assessed empirically in the next section.

The world economy consists of two countries: Home (also called the domestic economy) and Foreign (indicated by “*”). Each country has a one-sector economy, where firms produce horizontallydifferentiated goods. Home is a small open economy (SOE) in the sense of Demidova and Rodriguez-

\footnotetext{
${ }^{5}$ The Melitz (2003) heterogeneous firm model has other extensions that allow for heterogeneous wages. Among them, Amiti and Davis (2012), Kreickemeier and Egger (2009), Helpman, Itskhoki, and Redding (2008), and Helpman and Itskhoki (2010) feature wages that are proportional to firm size; however, if the payroll tax mechanism proposed here is applied to these models, all small firms will hire only informal workers, which is not supported by the findings discussed earlier. One shortcoming of the Davis and Harrigan (2011) model is that the firm-specific wage does not vary with the firm's profits. This is contrary to the findings for Indonesia by Amiti and Davis (2012).
} 
Clare (2011) and Davies and Paz (2011). That is, domestic policies only affect Foreign via the trade flow between the two countries. This assumption is justified on the grounds that a typical developing country has a small impact on aggregate international trade flows.

\section{Preferences and Demands}

Workers are risk-neutral and have identical standard Dixit-Stiglitz constant elasticity of substitution (CES) preferences that are defined over a continuum of horizontally-differentiated goods, indexed by $\omega \in \Omega$. There are no unemployment benefits, and each worker's income sources are wages and governmental lump-sum transfers $(t r)$. The latter is taken as given by the workers. Although workers inelastically supply their homogeneous labor, they each choose a level of effort $(e)$. The indirect utility of a worker $\left(V_{i}\right)$ employed at firm $i$ that pays a wage $W_{i}$ and faces a price index $P$ is

$$
V_{i}\left(W_{i}, e, P, t r\right)=\left\{\begin{array}{cc}
\left(W_{i}+t r\right) P^{-1} & \text { if worker shirks } \\
\left(W_{i} / e+t r\right) P^{-1} & \text { if worker exerts effort } \\
\operatorname{tr} P^{-1} & \text { if worker is unemployed }
\end{array}\right.
$$

The demand for each variety $\omega$, denoted by $q(\omega)$, is derived from the consumer expenditure minimization problem and is $q(\omega)=p(\omega)^{-\sigma} P^{\sigma} Q$, where $p(\omega)$ is the price of variety $\omega$ paid by the Home consumer, $Q$ is the Dixit-Stiglitz aggregate consumption level of the economy, and $\sigma$ is the elasticity of substitution across varieties.

\section{Firms' Technology}

Each firm produces a single different variety of the horizontally differentiated good using labor as the only factor of production. Firms are risk-neutral and heterogeneous both in their productivities $\left(\varphi_{i}, \varphi_{i} \geq 1\right)$ and monitoring abilities $\left(m_{i}, m_{i} \in(0, \bar{m}]\right.$ where $\bar{m}$ is the maximum monitoring ability). The monitoring ability or, equivalently, the employer's ability to detect a worker that is shirking her duties generates wage heterogeneity through efficiency wages paid to motivate workers to exert 
effort. ${ }^{6}$ Notice that such wage heterogeneity is not related to firm size or workers' characteristics. ${ }^{7}$

A worker can lose her job because of exogenous firm death (at a rate $\delta$ ) or after being apprehended shirking her duties. Accordingly, the lack of perfect monitoring ability induces firms to pay an efficiency wage to prevent workers from shirking. The solution to this efficiency wage problem is similar to the derivation in Davis and Harrigan (2011). ${ }^{8}$ Let $W_{1}$ denote the efficiency wage paid by the domestic firm with the greatest monitoring ability. Consequently, given the inverse monitoringwage nexus, $W_{1}$ is the lowest efficiency wage paid. The wages associated with the other monitoring ability levels are proportional to $W_{1}$ and given by a monotonically decreasing relationship between $W_{i}$ and $m_{i}$, which is described in equation (2).

$$
W_{i}=W_{1} \frac{\bar{m} e m_{i}}{m_{i}-\delta(e-1)}
$$

Notice that equation (2) implies that $\partial W_{i} / \partial m_{i}<0$. It also allows firms to be fully characterized by the joint distribution of productivity and wages, $\Psi(\varphi, W)$.

I assume that upon entry, a firm has to pay a one-time fixed entry cost of $f_{e}$ units of labor to discover its productivity-monitoring ability (or wage) draw. On the basis of this information, the firm then decides whether or not to operate and if so, which markets to serve. To supply the domestic market, firms incur a per-period fixed cost of $f$ units of labor and a labor requirement of $\varphi_{i}^{-1}$ per unit produced (also called the variable-cost activity). To serve the Foreign market, firms have to pay a per-period fixed export cost of $f_{x}$ units of labor, and the Foreign country import tariff, which is modeled as an iceberg transportation cost, so that a domestic firm ships $\tau^{*}$ units and the Foreign consumer receives one unit, Foreign import tariff $\equiv \tau^{*}-1>0$. Hence, the labor requirement for each unit exported is $\tau^{*} \varphi_{i}^{-1}$. In order to generate the fact that not all domestic

\footnotetext{
${ }^{6}$ According to Dasgupta and Ray (1986) and Ray (1998), efficiency wages in developing countries are motivated by the fact that a worker's physical strength (provided and determined by her nourishment) affects her effort level, so different monitoring abilities could be interpreted as different effort requirements. The effort level is also called 'labor power', and can include mental strength. Hence, a higher wage implies better nourishment, which means the worker is able to exert more effort.

${ }^{7}$ Schmidt and Zimmermann's (1991) findings corroborate the existence of wage heterogeneity even after controlling for firm size and worker characteristics. Using a panel of French firms and workers, Abowd et al. (1999) found that most of the heterogeneity in inter-industry wages is due to worker fixed effects and not firm effects. Krishna et al. (2011) also found that, for Brazil, worker innate ability and the quality of the worker-firm match explain most of within-industry wage variation. Nevertheless, Frias et al. (2009), using a different identification strategy, found that even after accounting for worker innate ability and match quality, there was still a relevant amount of wage heterogeneity. In sum, there is still variation that could not be explained. See Schank et al. (2007) for a survey on matched employer-employee data papers.

${ }^{8}$ The complete derivation of the efficiency wage problem is presented in the Appendix A.1.
} 
firms choose to export, I follow Melitz (2003, p. 1709) and assume that $f_{x} \tau^{* \sigma-1}>f$. Following Davis and Harrigan (2011), workers who are engaged in fixed-cost activities $\left(f_{e}, f\right.$, and $\left.f_{x}\right)$ receive a wage of $W_{1}$, and those performing variable-cost activity earn the efficiency wage, $W_{i}{ }^{9}$

The profit $\left(\pi_{i, d}\right)$ of a firm serving the domestic market is given by equation (3), where $b_{i}$ is the cost of the labor employed in the variable-cost activity. Such labor cost depends on the firm's choice of labor contracts, which will be discussed shortly.

$$
\pi_{i, d}=p_{i, d} q_{i, d}-W_{1} f-b_{i} \frac{q_{i, d}}{\varphi_{i}}
$$

The Foreign demand for a Home-produced variety is given by $q_{i, x}=p_{i, x}^{-\sigma} A$, where $A \equiv Q^{*} P^{*-\sigma}$. The SOE assumption makes $A$ constant. If a firm decides to export, its profit from exporting is:

$$
\pi_{i, x}=p_{i, x} q_{i, x}-W_{1} f-\tau^{*} b_{i} \frac{q_{i, x}}{\varphi_{i}}
$$

\section{Labor Contracts}

I assume that firms can hire workers who perform the variable-cost activity by using either formal or informal labor contracts. Under a formal contract, the firm complies with payroll taxes. In particular, it pays an ad valorem payroll tax $(t)$ and a per-worker administrative cost $(\Theta)$, which encompasses the costs of calculating, preparing, and maintaining tax records. ${ }^{10}$ The per-worker administrative cost consists of $\theta$ units of labor that also receive wage $W_{1}$ with no payroll tax incidence, like the labor used in the fixed-cost activities. Thus, the cost of a formal worker for firm $i$ is $b_{i}^{f o r}=T W_{i}+\Theta$, where $T \equiv 1+t$. Alternatively, the firm may choose not to comply with payroll taxes, i.e., use an informal labor contract. Yet, every firm is audited with probability $\zeta$, and if a firm is caught employing informal workers, it has to pay an ad valorem fine $\eta(\eta>t)$ that is based on the wage paid to each informal worker. ${ }^{11}$ Hence, firm $i$ 's expected cost of an informal worker is $b_{i}^{\text {inf }}=\lambda W_{i}$, where $\lambda \equiv 1+\eta \zeta .^{12}$

The likelihood of a payroll tax audit depends on the government's ability to detect the existence

\footnotetext{
${ }^{9}$ Helpman and Itskhoki (2010) also abstracted from wage distortions in the fixed costs activities. The assumption that every firm faces the same fixed costs ensures the existence of general equilibrium in the model.

${ }^{10}$ Evans (2003) provides evidence about the large private costs of tax compliance. Boisvert et al. (2001) found that in the case of Brazil, the cost of preparing tax records can be substantial, ranging from 43 to 86 dollars per worker, or between 15 and $30 \%$ of the prevailing minimum monthly wage.

${ }^{11}$ The formula used here to compute the fine is the one used in Brazil, as required by Laws 8212 and 9876.

${ }^{12}$ Schneider and Enste (2000) provide an in-depth discussion of the factors influencing regulation compliance.
} 
of firms. A firm that serves only the domestic market has to be found by government auditors, so the audit likelihood is $\zeta=\bar{\zeta}<1$. On the other hand, an exporting firm can be detected easily because the government monitors borders, and the trade flow information can then be matched to payroll tax data uncovering any evasion. This rules out the possibility that an exporter employs formal workers for export orders and informal workers for domestic orders. ${ }^{13}$ Another possibility is that firms exposed to international markets may have to follow a different set of rules enforced by Foreign or by international organizations, e.g., Fair Trade certification. ${ }^{14}$ Thus, exporters are more likely to be audited, and for the sake of simplicity, I assume that $\zeta=1$.

Because my interest is to study an economy in which both formal and informal jobs coexist in the same industry, I further assume that $\eta-t>\theta>\eta \bar{\zeta}-t>0$. The first inequality, $\eta-t>\theta$, ensures that informal workers are more expensive than formal workers whenever $\zeta=1$. So, exporting firms always hire formal workers. The second inequality, $\theta>\eta \bar{\zeta}-t>0$, guarantees the existence of a non-empty interval of wages in which the expected cost of an informal worker is smaller than the expected cost of a formal worker for a non-exporting firm. Since all large firms are exporters in my model, another interpretation of this assumption is that large firms are more likely to be audited, which is also in line with the third stylized fact. ${ }^{15}$

Figure 2 shows the expected cost of a formal and an informal worker for a firm that serves only the domestic market and for an exporting firm. A formal worker is cheaper than an informal worker for a non-exporting firm $i$ if its respective wage is $W_{i}>\chi \equiv \Theta /(\lambda-T)$. Notice that the wage cutoff $(\chi)$ is decreasing in $\eta$ and $\zeta$, which means that either an increase in the fine or an increase in the likelihood of an audit will decrease the cutoff. Conversely, an increase in either the payroll tax or the administrative cost leads to an increase in the cutoff. These properties are consistent with findings that both taxation and its enforcement are determinants of the informal economy (cf. Schneider and Enste, 2000).

The payroll tax revenues and fines collected are returned via lump-sum transfer $(t r)$ to all unemployed and employed (formal and informal) workers. In my model, the formal workers receive no benefit from the payroll taxes. This means that workers are ex ante indifferent between formal

\footnotetext{
${ }^{13}$ Munk (2008) discusses the administrative cost of several types of taxes and suggests that border tariffs are both the easiest to implement and the cheapest in terms of administrative and monitoring costs.

${ }^{14}$ See Alm et al. (1992) for a survey on other than pecuniary reasons for tax compliance.

${ }^{15}$ It seems reasonable that the audit probability should increase with firm size; however, this case is not analytically tractable, and the results would not be qualitatively different.
} 
and informal jobs, and in equilibrium, it is up to the firm to decide whether to offer formal or informal jobs. This feature is also present in the models of Goldberg and Pavcnik (2003) and Alemán-Castilla (2006).

The workers' indifference between formal and informal jobs can be justified on two fronts. First, in many developing countries, social security is a pay-as-you-go system, in which workers tend to see their contributions as simply a tax because the benefits they receive are weakly related to the contributions they make (for evidence supporting this point, see Kugler and Kugler, 2009; and Kumler et al., 2012). Furthermore, it is not clear that workers actually benefit from social security, since the rate of return on social security contributions may be smaller than the return on risk-free assets. Moreover, the frequent changes in rules end up discrediting the system and making workers less willing to contribute. Second, suppose that workers actually have some sort of non-pecuniary benefit from a formal labor contract. Gruber (1997) and Kugler and Kugler (2009) present evidence that the cost of such benefits could have been passed down to workers in the form of lower wages. They find that this type of pass-through is very large, sometimes reaching 100\%, making workers indifferent between receiving no benefits and receiving benefits that they have to pay for. ${ }^{16}$

So far, my model differs from Alemán-Castilla's (2006) in two important ways. Notice that Alemán-Castilla (2006) considers a Melitz type of model with payroll taxes. In his model, firms choose whether to comply with taxes and enjoy a larger productivity, or evade taxes and keep their initial productivity level draw. Although the argument that payroll tax compliance allows firms access to cheaper sources of capital is appealing, even large firms in developing countries are credit-constrained, so this does not seem to be a relevant mechanism. Furthermore, in his model, all small firms hire informal workers. And this result is not supported by the stylized facts discussed earlier.

In my model, firms exhibit the same productivity regardless of their choice of labor contract. Second, the wage heterogeneity in my model allows for some small firms to hire formal workers, and as we will see in the comparative statics of my model, such distinction plays a crucial role in the determination of the effects of trade policies on informality. Notice that the wage heterogeneity also leads to predictions involving the average formal and informal wages, as will be soon discussed.

\footnotetext{
${ }^{16}$ See Kugler (2011) for a survey on this topic.
} 


\section{General Equilibrium}

To characterize the general equilibrium of the model, the first step is to lay out the firm optimal labor contract decision, in order to define the marginal cost-based cutoffs used to classify firms according to the markets served and type of labor contract used. Like in Melitz (2003), these cutoffs are used in the derivation of the free entry, the zero profit, and the labor market clearing conditions. Last, I derive the remaining equilibrium conditions, including the trade balance condition that is now required due to the SOE assumption, as in Demidova and Rodriguez-Clare (2011).

Given that firms are risk-neutral, they choose whether or not to comply with payroll tax regulations based on their expected profits. Consequently, firms must choose between staying out of the market due to negative profits, producing only for domestic consumers using informal workers, producing only for domestic consumers using formal workers, or producing for domestic and foreign consumers using formal workers. Firm $i$ 's ex post profit is given by $\pi_{i}=\max \left\{0, \pi_{i, d}^{\mathrm{inf}}, \pi_{i, d}^{\text {for }}, \pi_{i, d}^{\text {for }}+\pi_{x, d}^{\text {for }}\right\}$

Let $s_{i}$ be the inverse of firm $i$ 's marginal cost, $s_{i}\left(W_{i}, \varphi_{i}\right) \equiv \varphi_{i} / b_{i}$. The entry cutoff $\left(s_{\text {open }}\right)$ is defined as the inverse of the marginal cost at which firms make zero profit. This means that firms with $s_{i}<s_{\text {open }}$ do not operate. Similarly, the inverse of the marginal cost at which firms make zero profit from exporting is defined as $s_{x, f o r} \equiv \inf \left\{s_{i}: \pi_{i, d}^{f o r}+\pi_{x, d}^{f o r}>\max \left[\pi_{i, d}^{\text {inf }}, \pi_{i, d}^{f o r}\right]\right\}$, which takes into account not only the export decision of firms employing formal workers but also the export decision of firms employing informal workers that have to switch to formal workers in order to supply foreign markets.

Figure 3 shows the entry cutoffs in the wage-productivity space. The diagonal lines represent $s$, and their slopes are the marginal cost $(b / \varphi)$; therefore, the flatter the line, the lower the marginal cost and the higher the employment level. The active firms are on the right-hand side of the $s_{\text {open }}$ curve, and the firms on the left-hand side choose to stay out of the market as soon as they learn their productivity and monitoring ability draws. The exporting firms are located on the right-hand side of $s_{x, f o r}$. This implies that exporters will be large firms. The firms that employ informal workers are located inside the polygon ABCD. ${ }^{17}$ This means that firms serving the domestic market, with $s$ between $s_{\text {open }}$ and $s_{x, \text { for }}$, will hire either formal or informal workers depending on the wage paid. So, not all small firms will hire informal workers, as indicated by the stylized facts discussed

\footnotetext{
${ }^{17}$ Because the difference between the informal and formal wage bills decreases in $W_{i}$ for $W_{i}<\chi$, the segment $\mathrm{AB}$ belongs to the line $T W_{i}+\Theta=\varphi_{i} / s_{x, \text { for }}$.
} 
previously.

Let $G(s) \equiv \operatorname{Pr}[S \leq s]$ be the cumulative distribution function of $s$, with its density given by $g(s)$. Following Melitz (2003), the $\sigma-1$ uncentered moment of $g(s)$ is assumed to be finite; and for the sake of integrability, I assume that $\sigma>3$. This latter assumption is also made by Helpman et al. (2004), and it does not appear to be restrictive because the empirical estimates of $\sigma$ by Hummels (2001), Romalis (2007), and Broda et al. (2008) are above 3.

The free entry condition states that a sufficient mass of ex ante identical firms enters the market so that the expected profit from entry equals the fixed cost of entry, as depicted in equation (5), where $J(\tilde{s}) \equiv\left[\left(\int_{\tilde{s}}^{\infty} \frac{s^{\sigma-1}}{\widetilde{s}} G(s) d s\right)^{\sigma-1}-1\right]$.

$$
J\left(s_{\text {open }}\right) W_{1} f+J\left(s_{x, f o r}\right) W_{1} f_{x}=\delta f_{e} W_{1}
$$

The number of workers in the entry fixed-cost activity is determined by the fact that, in the steady state, the mass of active firms does not change, so the mass of entrants should be enough to replace the firms that experienced a negative shock and left the market, $L^{e}=\delta M f_{e}\left[1-G\left(s_{\text {open }}\right)\right]^{-1}$, where $M$ is the mass of active firms in Home. The level of employment in the per-period fixed-cost activity is $L^{f}=M f$, and the level of employment in the per-period export fixed-cost activity is $L^{x}=\left[1-G\left(s_{x, f o r}\right)\right] M f_{x}$. Thus, the labor market clearing condition is given by:

$$
(1-u) L=L^{e}+L^{f}+L^{x}+(1+\theta) L^{v, f o r}+L^{v, \text { inf }}
$$

where $L^{v, f o r}=E\left[\frac{q_{i, d}}{\varphi} \mid \pi_{i, d}^{f o r} \geq \pi_{i, d}^{\mathrm{inf}} \geq 0\right]+E\left[\frac{q_{i, x}}{\varphi} \mid \pi_{x, d}^{\text {for }} \geq 0\right]$ is the number of formal workers in the variable-cost activity, $L^{v, \inf }=E\left[\frac{q_{i, d}}{\varphi} \mid \pi_{i, d}^{\text {inf }} \geq \pi_{i, d}^{\text {for }} \geq 0\right]$ is the number of informal workers in the variable-cost activity, $L$ is the labor force, and $u$ is the unemployment level, which is pinned down by equation (7) that is derived from the solution of the efficiency wage problem,

$$
u=\left[\frac{B_{1} E\left(\frac{W_{i}}{m_{i}}\right)}{W_{1}+B_{1} E\left(\frac{W_{i}}{m_{i}}\right)}\right]
$$

where $B_{1} \equiv\left[\frac{\bar{m} \delta(e-1)}{\bar{m}-\delta(e-1)}\right]$. Notice that $u$ depends upon $E\left(W_{i} / m_{i}\right)$, which is the expected wage distortion per unit of mass of active firm. Let $\psi\left(i \mid s^{*}\right)$ be the probability distribution function of active firms, where the firm type is given by $i(\varphi, m)$. Thus, the employment weighted average wage 
distortion is as follows:

$$
E\left(\frac{W_{i}}{m_{i}}\right)=\left(L^{e}+L^{f}+L^{x}+\theta L^{v, f o r}\right) \frac{W_{1}}{\bar{m} M}+\int \frac{q_{d, i} W_{i}}{\varphi_{i} m_{i}} \psi\left(i \mid s_{\text {open }}\right) d i+\int \frac{q_{x, i} W_{i}}{\varphi_{i} m_{i}} \psi\left(i \mid s_{x, f o r}\right) d i
$$

The per capita government transfer is the sum of collected payroll taxes and the expected value of the fines, where $\bar{w}^{\text {for }}$ is the average formal wage and $\bar{w}^{\text {inf }}$ is the average informal wage,

$$
t r=\frac{t \bar{w}^{\text {for }} L^{v, f o r}+\eta \zeta \bar{w}^{\inf } L^{v, \inf }}{L}
$$

The price index faced by the Home consumer is given by equation (10), where $M^{*}$ is the mass of active firms in Foreign that is exogenous due to the SOE assumption.

$$
P^{1-\sigma}=\frac{M}{1-G\left(s_{\text {open }}\right)} \int_{\text {sopen }_{\text {op }}}^{\infty}(\rho s)^{\sigma-1} d G(s)+\frac{M^{*}}{1-G^{*}\left(s_{x, \text { for }}^{*}\right)} \int_{s_{x, \text { for }}^{*}}^{\infty}\left(\frac{\rho s}{\tau}\right)^{\sigma-1} d G^{*}(s)
$$

The final equation that is required to solve for the general equilibrium states that trade flows between Home and Foreign must be balanced. This condition is not required when dealing with symmetric countries and symmetric tariff changes, as in Alemán-Castilla (2006) and Davis and Harrigan (2011). Nevertheless, it is required here because my model allows not only for asymmetric country sizes but also for asymmetric changes in tariffs. Consequently, sales from Home to Foreign must be equal to sales from Foreign to Home, as shown by equation (11).

$$
\frac{M}{1-G\left(s_{x, f o r}\right)} \int_{s_{x, f o r}}^{\infty}\left(\frac{\rho s}{\tau^{*}}\right)^{\sigma-1} A d G(s)=\frac{M^{*}}{1-G^{*}\left(s_{x, f o r}^{*}\right)} \int_{s_{x, f o r}^{*}}^{\infty}\left(\frac{\rho P s}{\tau}\right)^{\sigma-1} Q d G^{*}(s)
$$

Proposition 1. The general equilibrium is characterized by the solution of the system of equations comprised by equations (5)-(10) and the entry and export cutoff equations. This solution is unique. ${ }^{18}$

\footnotetext{
${ }^{18}$ The proofs for all Lemmas and Propositions appear in Appendix A.2.
} 


\subsection{Comparative Statics}

The comparative steady-state analysis presented here assesses the effects of changes in Home and Foreign import tariffs on the share of informal workers and on the average formal and informal wages in the Home country. Such outcomes are very convenient measures because they are expressed as ratios, which simplifies the derivations considerably since the general equilibrium effects on $P, Q$, and $M$ do not affect the signs of the derivatives. First, let us evaluate the effect of tariffs on the model's key variables $W_{1}$ and $s_{x, \text { for }}$. Next, I will discuss my theoretical model predictions regarding industry-level informality share and average wages, and their relation with the literature.

A reduction in Home import tariffs forces a reduction in $W_{1}$ to promote exports in order to offset the increase in imports and keep the trade flows balanced. Recall that the ratio between wages $\left(W_{i}\right)$ and $W_{1}$ is always constant, so in this case, a decrease in $W_{1}$ causes every Home wage to decrease proportionately and the formal-informal cutoff $(\chi)$ to change proportionately as well. The decrease in $W_{1}$ also leads to a decrease in $s_{x, f o r}$, which is indicated by a leftward rotation of

the $s_{x, f o r}$ line in Figure 3. The free entry condition, equation (5), implies that $s_{\text {open }}$ moves in the opposite direction from $s_{x, \text { for }}$. Thus, a decrease in $\tau$ increases $s_{\text {open }}$, i.e., the $s_{\text {open }}$ line in Figure 3 rotates to the right.

By similar reasoning, a reduction in Foreign import tariffs $\left(\tau^{*}\right)$ decreases $s_{x, \text { for }}$ and increases Home exports to Foreign. The trade-balanced equation implies that $W_{1}$ has to increase in order to offset the surge in exports. Since $s_{\text {open }}$ moves in the opposite direction from $s_{x, f o r}$, a decrease in $\tau^{*}$ leads to an increase in $s_{\text {open }}$. These results are formalized in Lemma 1.

Lemma 1. A decrease in Home tariffs leads to an increase in $s_{\text {open }}$ as well as a reduction in $W_{1}$ and $s_{x, \text { for }}$. On the other hand, a decrease in Foreign tariffs leads to a reduction in $s_{x, f o r}$, and an increase in $s_{\text {open }}$ and $W_{1}$.

\section{Effects of Tariffs on the Share of Informal Workers}

The share of informal workers is defined as share $\equiv L^{V, \text { inf }} /\left(L^{V, \text { inf }}+L^{V, f o r}\right)$. Besides being an informality measure widely used in the literature, it is useful for policymakers because it is a reliable indicator of the actual size of the payroll tax base. The effect of a change in Home import tariffs on the informal share is derived in equation (12). 


$$
\frac{d \text { share }}{d \tau}=\frac{\partial \text { share }}{\partial s_{\text {open }}} \frac{\partial s_{\text {open }}}{\partial \tau}+\frac{\partial \text { share }}{\partial s_{x, \text { for }}} \frac{\partial s_{x, \text { for }}}{\partial \tau}
$$

The decrease in the marginal cost entry cutoff induced by a reduction in the Home import tariff leads to a loss of both formal and informal jobs for Home firms. Hence, the sign of the first term on the right-hand side of equation (12) is indeterminate. The second term in the right-hand side of equation (12) reflects the increase in the marginal cost export cutoff that is due to the decrease in $\tau$. The Home firms in the $s_{x, f o r}$ locus with $W_{i}<\chi$ switch from informal to formal workers in order to gain access to foreign markets, and firms with $W_{i} \geq \chi$ hire more formal workers to engage in exporting. Since formal jobs are created and informal jobs are eliminated, the share of informal workers decreases. Lemma 1 implies that $s_{x, f o r}$ is decreasing in $\tau$; as a result, the second term of equation (12) is positive. Along these lines, the resulting sign of $d s h a r e / d \tau$ is ambiguous not because of the inability to sign the expressions but due to the fact that informal jobs are eliminated and formal jobs are both created and eliminated. This ambiguity should be interpreted as an important feature of the model, making it flexible enough to reconcile with the mixed empirical evidence discussed earlier. In Proposition 2, I present sufficient conditions that, if met, provide a sign for the effect of tariffs on the informality share.

Proposition 2. The effect of a reduction in the Home import tariff on the share of informal workers in total industry employment is ambiguous.

a. If condition (S1) holds, i.e., $0>\frac{\partial \Psi}{\partial \varphi} \Psi^{-1}>\frac{1-\sigma}{\varphi}$, then the share of informal workers will decrease with a reduction in $\tau$.

b. If conditions (S2) and (S3) hold, which are $\frac{1-\sigma}{\varphi}>\frac{f}{f_{x}}\left[1+\left(\frac{\sigma f_{x} \tau^{*}}{A \rho}\right)^{\frac{1}{\sigma-1}}\right] \frac{\partial \Psi}{\partial \varphi} \Psi^{-1}$ and $\operatorname{Pr}[W \geq \chi]>$ $\tau^{\sigma}\left(\frac{f}{f_{x}}\right)^{\frac{\sigma}{\sigma-1}} \operatorname{Pr}[W<\chi]$, respectively, then the share of informal workers will increase with a reduction in $\tau$.

Though these sufficient conditions may appear somewhat cumbersome, the intuition behind

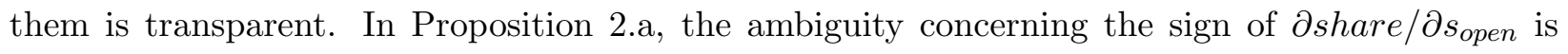
solved by making the number of formal jobs along the $s_{x, f o r}$ locus is larger than the number of formal jobs along $s_{\text {open }}$. This implies $\mid \partial$ share $/ \partial s_{x, f o r}|>| \partial L^{V, f o r} / \partial s_{\text {open }} \mid$, which holds under sufficient condition (S1). Condition (S1) means that the decrease in $\Psi(\varphi, W)$ induced by the increase in $\varphi$ is smaller than the increase in the employment also generated by the increase in $\varphi$. 
For a given wage, these assumptions imply that the change in the formal employment of firms lying on $s_{x, f o r}$ is larger than the change in the formal employment of firms lying on $s_{\text {open }}$.

On Proposition 2.b, we have the opposite case. Here, the ambiguity is addressed by imposing sufficient conditions (S2)-(S3) that lead to more formal jobs being eliminated along $s_{\text {open }}$ than formal jobs created along $s_{x, \text { for }}$ and informal jobs eliminated along $s_{\text {open }}$ and $s_{x, \text { for }}$. Intuitively, conditions (S2)-(S3) imply that the majority of small firms will hire formal workers. Thus, (S2)-(S3) leads to a smaller initial industry-level share of informality than condition (S1). Both cases, however, are compatible with McCaig and Pavcnik's (2012) findings of labor reallocation. So, one possible interpretation is that for a given payroll tax and enforcement, a tariff decrease in an economy with an initial high informality level leads to a reduction in the informality share, whereas the same change in an economy with a low initial informality results in an increase in informality share. In the empirical section, I show that in the 1989-2001 Brazilian trade liberalization, the informality share increases with a decline in the import tariffs.

In the literature, the effect of a decrease in import tariffs is also modeled in Goldberg and Pavcnik's (2003) partial-equilibrium model. Such tariff cut works through a decrease in the price of the good produced, which in turn leads to a decrease in the number of formal workers while the number of informal workers remain fixed; as a result, the share of informal workers increases. Given McCaig and Pavcnik's (2012) findings do not corroborate Goldberg and Pavcnik's (2003) result that the number of informal jobs do not vary.

The derivation of the effect of a reduction in Foreign import tariffs on the Home share of informal workers is similar to Proposition 2. Nevertheless, as shown in equation (13), the derivative of the informality share with respect to $\tau^{*}$ includes an additional term because now $\tau^{*}$ affects the share of informal workers directly.

$$
\frac{d \text { share }}{d \tau^{*}}=\frac{\partial \text { share }}{\partial s_{\text {open }}} \frac{\partial s_{\text {open }}}{\partial \tau^{*}}+\frac{\partial \text { share }}{\partial s_{x, \text { for }}} \frac{\partial s_{x, \text { for }}}{\partial \tau^{*}}+\frac{\partial \text { share }}{\partial \tau^{*}}
$$

Besides changing the entry and export cutoffs as discussed earlier, a decrease in the Foreign import tariff affects the Home share of informal workers by increasing the formal employment by current exporting firms in response to the increase in the volume exported. This is indicated by the last term on the right-hand side of equation (13), which is positive. Hence, the same type of 
sign ambiguity seen in Proposition 2 is present here. Nonetheless, this ambiguity can be solved by using a similar strategy to that of Proposition 2. Conditions (S2) and (S3) are not enough to obtain an opposite sign prediction anymore due to the positive direct effect of $\tau^{*}$ on the share.

Proposition 3. The effect of a reduction in the Foreign import tariff on the share of informal workers in total industry employment is ambiguous. If sufficient condition (S1) holds, then a reduction in $\tau^{*}$ will decrease the share of informal workers in total industry employment.

This result cannot be compared directly with other models' results because they either simply ignored the role of $\tau^{*}$ or modeled symmetric tariff changes as in Alemán-Castilla's (2006) theoretical model. Alemán-Castilla's (2006) model predicts that a symmetric decrease in tariffs' effect on the informality share is ambiguous. In my model, such symmetric tariff reduction leads to the elimination of informal jobs and the creation and destruction of formal jobs, whereas his model predicts the creation and destruction of both formal and informal jobs, since some firms would switch from formal to informal workers. This different result comes from Alemán-Castilla's (2006) assumption that formality leads to a productivity boost. Unfortunately, the lack of firm-level data on payroll tax compliance prevents further scrutiny of these mechanisms.

\section{Effects of Tariffs on the Average Formal and Informal Wages}

The average formal (informal) wage is defined as the simple average of the formal (informal) workers' wage. These average wage measures not only allow us to evaluate changes in wage inequality between average formal and informal workers but also are important and easily measurable components of worker welfare. The effects of a reduction in the Home import tariff on the average formal wage are presented in equation (14). The equation for the effect on the average informal wage is analogous.

$$
\frac{d \bar{w}^{\text {for }}}{d \tau}=\left(\frac{\partial \bar{w}^{\text {for }}}{\partial s_{\text {open }}} \frac{\partial s_{\text {open }}}{\partial \tau}+\frac{\partial \bar{w}^{\text {for }}}{\partial s_{x, f o r}} \frac{\partial s_{x, f o r}}{\partial \tau}\right) \frac{d W_{1}}{d \tau}
$$

According to Lemma $1, W_{1}$ decreases in $\tau$, so the sign of the effect of $\tau$ on the average formal wage will be determined by the sign of the expression inside the parentheses in equation (14). These terms indicate the changes in the average wage due to the creation and elimination of jobs that pay different wages in response to tariff-induced changes in the entry and export cutoffs. For both the 
average formal and informal wages, the resulting sign of the import tariff effect is indeterminate.

Proposition 4. The effect of a reduction in the Home import tariff on the industry-level average formal wage is ambiguous. If the sufficient conditions (S4) and (S5) hold, where condition (S4) $\partial \Psi / \partial W<-\sigma T /(T W+\theta)$ and condition $(S 5)$ is $\partial \Psi / \partial \varphi<0$, a reduction in the Home import tariff will decrease the industry-level average formal wage.

To determine the sign of equation (14), let us contrast the average formal wage with the average wage of the formal firms that lie on the curve where the derivative is evaluated, in this case $s_{\text {open }}$ and $s_{x, f o r}$. For the import tariff effect to be positive, the average formal wage along $s_{\text {open }}$ would need to be larger than $\bar{w}^{\text {for }}$ and the average formal wage along $s_{x, f o r}$ would need to be smaller than $\bar{w}^{\text {for }}$. Thus, a decrease in $\tau$ eliminates jobs with above-average wages and creates jobs with below-average wages. If conditions (S4) and (S5) are satisfied, the average formal wage along $s_{\text {open }}$ will be higher than the average wage along $s_{x, \text { for }}$. Unfortunately, these sufficient conditions are not sufficient to prevent sign ambiguity concerning the effects of Home tariff changes on the average informal wage.

The effect of a reduction in the Foreign import tariff $\tau^{*}$ on the Home average formal wage also has an ambiguous sign because the sign of the term inside the parentheses in equation (15) is indeterminate. Notice that there is an additional term - the effect on the average formal wage due to the change in employment of current exporters.

$$
\frac{d \bar{w}^{\text {for }}}{d \tau^{*}}=\left(\frac{\partial \bar{w}^{\text {for }}}{\partial s_{\text {open }}} \frac{\partial s_{\text {open }}}{\partial \tau^{*}}+\frac{\partial \bar{w}^{\text {for }}}{\partial s_{x, f o r}} \frac{\partial s_{x, \text { for }}}{\partial \tau^{*}}+\frac{\partial \bar{w}^{\text {for }}}{\partial \tau^{*}}\right) \frac{d W_{1}}{d \tau^{*}}
$$

Proposition 5. The effect of a reduction in the Foreign import tariff on the industry-level average formal wage is ambiguous. If conditions (S4) and (S5) hold, a reduction in the Foreign import tariff will increase the industry-level average formal wage.

Similarly to Proposition 4, a positive sign for the term inside the parentheses is obtained if conditions (S4) and (S5) hold. Given that $d W_{1} / d \tau^{*}<0$, the effect of foreign tariff on the average formal wage is negative. As was the case for the reduction in the Home import tariff, these conditions are again insufficient to prevent sign ambiguity concerning the effects of tariff changes on the average informal wage. Lastly, notice that conditions (S1) and (S2) are compatible with 
condition (S5). Thus, the results of Propositions 4 and 5 are compatible with both cases (a or b) of Proposition 2.

\section{Econometric Methodology}

In my model, Brazil is the domestic country, while the Foreign country consists of an aggregate of Brazil's trade partners. Hereafter, for the sake of simplicity, Brazil's import tariff will be called $i m$ port tariff, and the import tariff imposed on Brazilian exports by the Foreign country will be called export tariff. The illegal nature of payroll tax evasion makes data collection very difficult. To the best of my knowledge, there are no datasets containing the characteristics of employers of informal workers according to the definition of informality used here; however, there are household surveys that ask workers about their employer's payroll tax compliance. These pooled cross-sectional data guided the econometric specifications developed here to assess my theoretical model testable predictions. I will first discuss the econometric specification used to assess the informality share predictions. Next, the specifications for the predictions involving the average formal and informal wages will be presented.

\subsection{Econometric Model of Informality Share}

The effects of changes in the import $(\tau)$ and export $\left(\tau^{*}\right)$ tariffs on the industry-level share of informal workers are estimated by modeling the worker-level probability of having an informal job $\left(\right.$ informal $_{i j t}^{*}$ ), as depicted by equation (16). In this specification, an increase in the probability of having an informal job is equivalent to an increase in the expected share of informal workers.

$$
\text { informal }_{i j t}^{*}=\beta_{0}+\beta_{1} \tau_{j t}+\beta_{2} \tau_{j t}^{*}+\alpha * \text { year }_{t}+\gamma * \text { industry }_{j}+\boldsymbol{\Xi} * \text { characteristics }_{i j t}+\varepsilon_{i j t}
$$

where informal ${ }_{i j t}^{*}$ is " 1 " if worker $i$ is employed in industry $j$ in year $t$ as an informal worker and "0" otherwise, year $_{t}$ is a vector of year indicator variables, industry ${ }_{j}$ is a vector of industry indicator variables, characteristics ${ }_{i j t}$ is a matrix of observable worker characteristics, and $\epsilon_{i j t}$ is the unobservable error term. ${ }^{19}$ Proposition 2.a predicts that a decrease in the import tariff will

\footnotetext{
${ }^{19}$ Equation (16) is a similar version of the two-step approach used by Goldberg and Pavcnik (2003) and Alemán-
} 
decrease the share of informal workers $\left(\beta_{1}>0\right)$, whereas Proposition 2.b suggest the opposite sign for $\beta_{1}$. Proposition 3 implies that a decrease in the export tariff will reduce the informality share $\left(\beta_{2}>0\right)$.

The year effects are included in the specification to control for economy-wide shocks, such as business cycles and exchange rates. For instance, if firms employing formal workers are more likely to reduce employment during a recession, and if, at the same time, the government raises tariffs in response to the recession, then a spurious relationship will be found between tariffs and the share of informal workers unless year effects are used.

Some industry-specific characteristics that are correlated with right-hand-side variables are certainly omitted, which will lead to inconsistent estimates. One example is the ability of firms to hide their operations from the government. It is easy for an apparel firm to hide itself since it can be small. But it is difficult for a steel mill to hide itself because it must be large due to technological constraints. As long as these industry characteristics remain stable over time, this problem can be addressed by adding industry effects to the econometric specification. Once year and industry effects are included, the identification of $\beta_{1}$ and $\beta_{2}$ will come from the within-industry variation of the tariffs over time, as postulated in my theoretical model.

The workers' observable characteristics are incorporated into equation (16) on the following grounds. It is important to account for worker heterogeneity because industries their technologies may have different labor skill requirements. In this case, the industry fixed effects will be correlated with worker characteristics. If the latter are in the error term, then the estimates will be inconsistent. Furthermore, worker heterogeneity can lead to worker self-selection into formal or informal jobs provided that the benefits and costs of formality vary according to worker observable characteristics. The characteristics used in the econometric specifications are age, age ${ }^{2}$, years of education, gender, and region of residence.

It is important to stress that following the literature, equation (16) has no control for modifications in the payroll tax and its enforcement, which are a key determinant of informality in my theoretical model. The payroll taxes did not change during the trade liberalization episode in Brazil (AEPS, 2005). But, the enforcement data suggests that the number of establishments visited by is estimated separately for every year of the sample. In the second step, these estimated industry affiliation effects are regressed (OLS) on trade-related measures, in addition to time and industry indicators. 
auditors has varied over the years. ${ }^{20}$

Almeida and Carneiro (2012) provided evidence that the enforcement of labor regulations (e.g., payroll tax) is not random. It seems to be heterogeneous over time and across Brazilian states; hence, I added state-by-year fixed effects to equation (16). ${ }^{21}$ Another finding by Almeida and Carneiro (2012) is that enforcement seems to be a function of non-compliance. Suppose that a decrease in the import tariff increases informality, and reduces payroll tax revenues. In order to raise revenues, the government increases enforcement (which is part of the error term), which reduces informality in my model. Consequently, cuts in import tariff lead to less informality and the OLS estimate will then be positively biased. Another possible interpretation for such endogeneity of import tariffs is that the potential loss in payroll tax revenue may have affected the setting of the import tariff, generating reverse causation between the share of informal workers and the import tariff.

To address these reverse causality issues, I use the Colombian import tariff that was set during Colombia's trade liberalization episode (from 1984 to the mid 1990s) as an instrument for the Brazilian import tariff. ${ }^{22}$ I match the year preceding the trade liberalization in Colombia (1984) to the year preceding trade reform in Brazil (1989). Hence, the 1984 Colombian tariff level is used as an instrument for the 1989 Brazilian import tariff, and so on. The correlation between these two import tariffs derives from the fact that, prior to their trade liberalization episodes, both the Colombian and Brazilian governments believed that their import substitution industrialization policies (which implied high levels of trade protection) were welfare-enhancing. In addition, the import substitution development policy was considered to be an institution, even an historical legacy, that could not be changed easily. ${ }^{23}$ At a certain point, however, governments realize that the gains from import substitution may not be as large as expected, and change their development

\footnotetext{
${ }^{20}$ The audited establishment series at a highly aggregate level starts in 1992, when 112,327 establishments were visited (AEPS, 2005). The number of visits increased to 144,069 in 1994 but declined to 89,000 in 2001 . The total number of establishment series for Brazil is available at IBGE (2011) from 1996 onward. This series indicates that the number of establishments increases monotonically every year, which causes the share of establishments audited per year to change over time.

${ }^{21}$ I'd like to thank an anonymous referee for suggesting the use of state-by-year effects.

${ }^{22}$ Several papers have used pre-reform tariff levels interacted with macroeconomic variables as instruments for tariff changes. The pooled cross-sectional nature of the data used here prevents the use of first difference, and macroeconomic variables such as exchange rates are endogenous in my model, which makes these instruments invalid. Karacaovali (2011) presents other important criticisms about this type of instrument.

${ }^{23}$ The idea that a country engaged in an import substitution development policy suddenly changes its mind toward trade liberalization was originally developed in Karacaovali (2011).
} 
policies by decreasing trade protection across all industries. ${ }^{24}$ This willingness to liberalize trade due to the change in development policy made Brazilian and Colombian tariffs to move in the same direction (i.e., downward). Hence they exhibit a positive correlation.

The Colombian import tariff is a valid instrument for the Brazilian import tariff, I believe, for the following reasons. First, Colombian tariffs are not affected by future Brazilian tariffs because trade between these two countries is very small relative to the trade flows they conduct with their other partners. Second, according to Goldberg and Pavcnik (2005), in the early 1980s, the Colombian government negotiated with the World Trade Organization (WTO) to set tariffs in order to achieve a uniform tariff of $13 \%$ across industries. Consequently, Colombian policymakers were less able to allow informality concerns to affect the tariff reduction. Third, the pre-reform protection patterns in Brazil and Colombia were different. As shown in Table 3, Colombia offered more protection to the light manufacturing sector (e.g., apparel and footwear), which has a large share of informal workers, while Brazil offered more protection to capital good industries (e.g., machinery and transportation equipment), which employ few informal workers. Fourth, although Colombia engaged in a labor market reform in the mid 1990s, such reforms happened a few years after the bulk of the tariff cuts and under a different president. Accordingly, these reforms could not have been anticipated at the time the tariff cuts were designed and implemented. Therefore, the possible effect of Colombia's informality on its tariffs appears to be uncorrelated with the effect of Brazil's informality on Brazilian tariffs.

Three more important econometric issues merit further discussion. First, the trade balance condition provides an important and subtle insight regarding regressors and instrument choice. Due to the fixed mark-up monopolistic competition framework, the exchange rate is given by the relationship between $W_{1}^{*}$ and $W_{1}$, and therefore is simultaneously determined with informality share. Moreover, in my model, import penetration and import and export volumes are also simultaneously determined with informality measures. The endogeneity of these variables has been overlooked in much of the empirical literature, such as Goldberg and Pavcnik (2003) and Alemán-Castilla (2006).

The second issue is that even though equation (16) includes the workers' observable characteristics, this specification still does not control for the workers' unobservable characteristics, which

\footnotetext{
${ }^{24}$ For instance, governments that adopted import substitution development policies could contrast their own economic performance with the performance of countries such as South Korea, which adopted different development policies.
} 
requires the use of panel data. The only panel data available comes from the Pesquisa Mensal de Emprego (PME), which is used by Menezes-Filho and Muendler (2011). The PME data, however, have several shortcomings. First, not only is this survey sample small (35 times smaller than the dataset used in this paper) but it also has a large attrition-in particular, workers with unstable jobs (presumably informal jobs) are more likely to move away and thus not be found by the interviewer. Second, in this survey, each worker is interviewed only two times, and these interviews are one year apart from each other. This interval between interviews may be too short to allow the observation of the effects of tariffs changes. Finally, the PME is not representative of the whole country since it covers only a few metropolitan areas that account for approximately half of Brazil's GDP. This is important because trade liberalization in Brazil had a significant impact on intra-country migration, as discussed in Kovak (2013), which implies even more attrition in the sample.

The last issue is that some of the variation in $\epsilon_{i j t}$ is likely to be common to workers in the same industry in a given year. So, the error term can be decomposed into two components- the industry-year shock and the idiosyncratic individual component. The former, if ignored, generates correlation across individuals in the same industry for a given year. Assuming that the industryyear shocks are serially uncorrelated, clustering the standard errors at the industry-year level (180 clusters) addresses such correlation across individuals and provides consistent estimates of the standard errors. Yet, the industry-year shocks could be correlated over time. Then, as pointed out by Bertrand et al. (2004) and Kézdi (2004), the standard errors estimated with industry-by-year clusters are not reliable. Angrist and Pischke (2008, p. 318) argue that there is still no consensus as to the best approach for addressing this problem. One solution suggested by them consists of clustering the standard errors at the industry level. This reduces the number of clusters to 15 in my data. Cameron et al. (2008) provide evidence that standard error estimates may not be reliable when the number of clusters is less than 20. Thus, this proposed solution has a side effect of also leading to bias in the estimated standard errors. The approach taken in this paper is to present estimates that use both types of clustered errors.

Equation (16) can be estimated with sample weights as a linear probability model using OLS and 2SLS. Nonetheless, neither estimator accounts for the dichotomous nature of the observed dependent variable, which could lead to several econometric problems. To address this issue, I 
consider informal ijt $_{\text {as a latent variable, and define the observable variable informal }}$ ijt to be " 1 " if informal $l_{i j t}^{*}>0$ and "0" otherwise, and then use Probit and IVProbit techniques to obtain consistent estimates.

\subsection{Econometric Model of Average Formal and Informal Wages}

Propositions 4 and 5 imply that wages and the informality status of a worker are simultaneously determined. To address this issue, I employ a switching regression model (Maddala, 1983), also called a 'Tobit type 5' model (Amemiya, 1985). The first step is to model the employment regime (formal or informal) selection. For this purpose, I use the equation (16), which is estimated by IVProbit. Next, I compute the inverse Mills ratio for each worker using the predicted values of informal ${ }_{i j t}^{*}$. The inverse Mills ratio is given by $\Lambda(z)=\phi(z) / \Phi(z)$, where $\phi(z)$ is the probability distribution function of a standard normal and $\Phi(z)$ is the cumulative distribution of a standard normal. Finally, to control for worker self-selection, I incorporate this calculated ratio into an augmented Mincer earnings equation for each employment regime, which also includes import and export tariffs, and year, industry, and state-by-year effects.

The use of Mincer earnings equations is suggested by Schmidt and Zimmermann (1991) findings that the different characteristics of workers lead to different wages. In my case, worker characteristics will affect not only the wage but also the type of labor contract, as discussed earlier. A byproduct of my empirical strategy is that it also controls for the effect of changes in average wages induced by skill composition of the workers. The earnings equation for formal workers and informal workers are equations (17) and (18), respectively.

$$
\begin{aligned}
& w_{a g e_{i j t}^{f o r}}=\Gamma_{0}^{f o r}+\Gamma_{1}^{f o r} \tau_{j t}+\Gamma_{2}^{f o r} \tau_{j t}^{*}+\alpha^{f o r} * \mathbf{y e a r}_{t}+\gamma^{f o r} * \text { industry }_{j}+ \\
& \boldsymbol{\Xi}^{\text {for }} * \text { characteristics }_{i j t}-\sigma_{\varepsilon v_{1}} \Lambda\left(-i n \widehat{\text { form }} a l_{i j t}^{*}\right)+v_{1, i j t} \\
& \text { wage }_{i j t}^{\text {inf }}=\Gamma_{0}^{i n f}+\Gamma_{1}^{i n f} \tau_{j t}+\Gamma_{2}^{i n f} \tau_{j t}^{*}+\alpha^{i n f} * \text { year }_{t}+\gamma^{\text {inf }} * \text { industry }_{j}+ \\
& \boldsymbol{\Xi}^{i n f} * \text { characteristics }_{i j t}-\sigma_{\varepsilon v_{2}} \Lambda\left(-i n \widehat{\text { form }} a l_{i j t}^{*}\right)+v_{2, i j t}
\end{aligned}
$$


The self-selection into formal or informal labor contract works through a non-zero correlation among $\epsilon, v_{1}$, and $v_{2}$ that, if not controlled for, can bias the estimates of the effect of tariffs on wages. If this correlation is non-zero, then the estimated coefficient of the inverse Mills ratio will be statistically significant.

Identification in this specification can be achieved by two strategies. The first is through the non-linearity of the functional form of $\Lambda$. This is effective as long as there is a large variation in in $\widehat{\text { form }} a l_{i j t}^{*}$ across observations (Cameron and Trivedi, 2005, p. 551), which is the case with the Brazilian data used herein. The second identification strategy requires the availability of at least one variable that matters in the regime selection equation, equation (16), and does not influence the wage received by the worker. I believe that a variable with such characteristics is the indicator variable if another person in the household has a formal job (otherformal ${ }_{i j t}$ ), which is also used by Roberts (1989) and Pratap and Quintin (2006). Notice that some formal job workplace benefits (e.g., health insurance) may cover the other members of the household. The perceived value of a formal job increases vis-à-vis an informal job if this worker can opt out of such benefits since she is already covered by another member of the household's policy. This suggests a negative coefficient in the selection equation. The justification comes from the fact that the worker is already covered by such benefits, and thus paying again for the same benefit will not affect worker's productivity, and therefore her wage.

The marginal effect of the export tariff on the formal wage is $\widehat{\Gamma}_{2}^{f o r}+\widehat{\sigma}_{\varepsilon v_{1}} \widehat{\beta}_{2} \Lambda\left(-i n \widehat{f o r m} a l_{i j t}^{*}\right)$

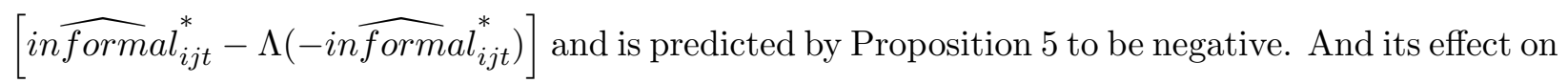
the informal wage is $\widehat{\Gamma}_{2}^{i n f}-\widehat{\sigma}_{\varepsilon v_{2}} \widehat{\beta}_{2} \Lambda\left(i n \widehat{\text { form }} a l_{i j t}^{*}\right)\left[{ }_{\text {inform }} l_{i j t}^{*}+\Lambda\left(\right.\right.$ in $\left.\left.\widehat{\text { form }} a l_{i j t}^{*}\right)\right]$. Similar marginal effects can be calculated for the import tariff, with Proposition 4 predicting a positive effect of import tariffs on the average formal wage.

I estimate these switching regressions using a two-step method that consists of first calculating $\Lambda$ with the predicted values from the IVProbit estimate, and then estimating equations (17) and (18) using the observations for formal workers and informal workers, respectively. Although this method is inefficient relative to maximum likelihood, it requires weaker distributional assumptions and imposes a lighter computational burden (Cameron and Trivedi, 2005 p. 550). Given the concern about the possible endogeneity of the import tariff variable, both wage equations are estimated using 2SLS and OLS. Because $\Lambda$ is a generated regressor, standard errors are calculated 
by a 500-repetition bootstrap that takes into account the original sample weights when conducting the resample.

The previous literature empirical strategy, as in Alemán-Castilla (2006), is based upon a different two step different strategy to examine the effect of tariffs on the formal-informal wage gap. First, the formal-informal wage gap is obtained by means of a Mincer-type specification using an informality status indicator variable as an exogenous regressor. The second step consists of regressing the estimated wage gap on tariffs. Notice that such empirical strategy has a major shortcoming. It does not generate consistent estimates of the wage gap because the informality indicator variable is determined simultaneously with the wage, and both are also affected by tariffs that are omitted in the first step. As a result, these formal-informal wage-gap estimates are inconsistent.

\section{Data and Historical Background}

In this section, I first describe the Brazilian worker-level data. Next, I present the import and export tariff data and the aggregation procedures used. Details regarding the construction of the variables are available in Appendix A.3.

\subsection{Worker Data}

The IBGE-Instituto Brasileiro de Geografia e Estatística (Brazilian Bureau of Geography and Statistics) conducts an annual household survey called 'Pesquisa Nacional por Amostra de Domicílios' (PNAD), which covers the entire country, with the exception of Northern rural areas. Together these areas account for less than $5 \%$ of the Brazilian population and have no manufacturing activity. These surveys ask workers about their demographics, employment characteristics, and their employers' labor regulation compliance. PNAD was not conducted in 1994 due to a lack of funds. In the census years of 1991 and 2000, it was not conducted either, but I use Brazilian census microdata from IPUMS-International (Minnesota Population Center, 2007), which contains the very same questions as the PNAD survey. Along these lines, with the exception of 1994, I use annual data for the 1989-2001 period.

The payroll tax compliance question has few missing observations, which account for at most $0.3 \%$ in each year of the sample. Workers have no incentive to answer incorrectly this question 
because the questionnaire is confidential and cannot be used as evidence in court. More importantly, informal workers in Brazil suffer no penalty if caught by the authorities; only employers are penalized. Finally, workers are aware of their status since a small share of the payroll tax is deducted from their wages.

The definition of informality used in empirical work is diverse. For instance, Goldberg and Pavcnik's (2003) model justifies informality by the existence of firing costs. In their empirical specifications, however, workers are not classified as formal or informal according to severance payment compliance. For Brazil, their sample includes employees and self-employed workers. They use the non-existence of a signed labor contract as an informality indicator. ${ }^{25}$ In Alemán-Castilla's (2006) theoretical model, the definition of informality is based on payroll tax compliance. Nevertheless, his empirical work uses a different definition of informality. In addition to payroll tax compliance, he also considers as informal workers people employed in firms with less than five workers as well as employees of firms that do not offer health insurance, which is not required by law.

In this paper empirical investigation, I will precisely follow my theoretical model definition of informality. Accordingly, only employees are considered, and they must be between 15 and 65 years of age. The age cutoff is chosen to exclude those who are not eligible to pay payroll taxes due to a lack of authorization to work, either because they are too young (the minimum age to work is 14) or are already receiving social security benefits (i.e., older than 65).

The industry aggregation level used is dictated by the PNAD industry classification, which consists of 15 manufacturing industries. I dropped the few observations that had missing data for any of the worker characteristics used. In the end, a total of 775,331 observations remained in the data set and were included in the analysis.

\subsection{Tariff Data}

Until the end of the 1980s, Brazil's trade policy was driven by an import substitution development policy and the country's balance of payments deficits. ${ }^{26}$ The former implied different levels and types of protection across industries, in particular high tariffs and non-tariff barriers on imported goods that competed with similar domestic products. The latter resulted in increased tariffs across

\footnotetext{
${ }^{25}$ Goldberg and Pavcnik (2003) used a different survey for Brazil: the PME. The PME has several problems that were discussed earlier.

${ }^{26}$ Kume et al. $(2003,2008)$ provide a good description of Brazil's trade policy in the 1980s and 90s.
} 
all industries to curb imports. In 1988, however, Brazil unilaterally decided to change its trade policy by reducing its tariffs to a level that would still prevent imports, but it did not change its non-tariff barriers (NTBs) as argued by Kume et al. (2003). In 1990, Brazil's new president drastically reduced NTBs and adopted nominal tariff reductions scheduled to start in 1990 and end in 1994 (see Kovak, 2013). The actual decrease in tariffs was not identical across industries, and can be seen as the difference between the maximum and the minimum import tariffs in Table 3 . In particular, the industries with the largest absolute decrease in import tariffs are apparel, textiles, pharmaceutical, rubber products, and automobiles. Moreover, the tariff reductions did not follow the planned schedule according to Kume et al. (2003, p. 15; 2008, p. 112). Nonetheless, the tariff reduction had real effects on the economy, as imports of manufactured goods increased by more than $200 \%$ and import penetration increased from $5.7 \%$ to $11.6 \%$ in the $1990-1998$ period. Figure 4 shows the behavior of the average Brazilian import tariff. We can see a sharp drop in tariffs in the early 1990s as discussed before and a slight increase in tariffs by 1995 due to the adoption of Mercosur's external common tariff.

The 1989-2001 Brazilian import tariff and the effective rate of protection (ERP) data come from Kume et al. (2003). ${ }^{27}$ The instrument for import tariffs is constructed using Colombian import tariff data at the 4-digit ISIC level for the 1984-1998 period from the Colombian National Planning Department (DNP), which were further aggregated to my 15-industry classification using simple averages.

Brazilian firms' access to these foreign markets also changed during the 1989-2001 period, for three reasons. First, the GATT Uruguay Round negotiations led the United States, Japan, the European Union, and other developed countries to decrease the tariffs levied on several trade partners, see Finger and Schuknecht (1999). Interestingly, Abreu (1996, p. 81) points out that developing countries had almost no influence on the agreed tariff cuts for developed countries. Second, starting in 1991, the Mercosur customs union almost eliminated tariffs for the majority of goods traded among its members — namely, Argentina, Brazil, Paraguay, and Uruguay. Third, in order to join the WTO during the 1990s, China decreased its import tariffs on WTO members.

The choice of Brazil's trade partners considered here is dictated by data availability. The partner countries used here are Argentina, China, Japan, the United States, France, Italy, Germany,

\footnotetext{
${ }^{27}$ The simple correlation coefficient between import tariffs and ERP is 0.85 .
} 
the United Kingdom, Belgium-Luxemburg, the Netherlands, Portugal, and Spain. Together they accounted for more than $60 \%$ of Brazil's manufacturing exports during the 1989-2001 period. ${ }^{28}$ The export tariff variable used in the estimates consists of the simple average of each trade partner's import tariff for each of my 15 industries.

These tariff reductions by Brazil's trade partners can be seen as the difference between the maximum and minimum export tariff in Table 3, and were accompanied by a $68 \%$ increase in Brazil's exports of manufactured goods during the 1990-1998 period. The industries with the largest decline in export tariffs are apparel, food and tobacco, textiles, footwear, and automobiles. Figure 5 shows the average export tariff across my 15 manufacturing industries. Notice that there is some decrease in tariffs from 1990 to 1994, which is due to the decrease in Argentina's import tariffs caused by the Mercosur agreement. After 1994, we have a pronounced decline in export tariffs due to the Uruguay round tariff cuts. By contrasting Figures 4 and 5, we can see that the changes in import and export tariffs happened at different points in time. This highlights the importance of breaking the symmetry of tariff changes in the theoretical model. ${ }^{29}$

\section{Empirical Evidence}

In this section, I first assess the predictions concerning the share of informal workers. Next, the average formal and informal wage specifications are estimated. Finally, I conduct several econometric robustness checks by estimating different specifications, which confirm the previous results and rule out the possibility that pre-existing trends in the data are driving the results.

\subsection{Share of informal workers}

The effects of changes in export and import tariffs on the industry-level share of informal workers are estimated using worker-level data by means of equation (16). Table 4 reports these estimates, where the standard errors are clustered at the industry-year level. Column (1) reports the OLS estimated tariffs coefficients for the linear probability model, which are not statistically significant. The Probit estimated coefficients, column (2), have a negative sign for import tariff (as predicted

\footnotetext{
${ }^{28}$ Mercosur is not the major destination of Brazilian exports. In particular, by 1994, the exports to Mercosur countries reached volumes close to the exports to the United States or the European Union.

${ }^{29}$ Once year and industry effects are accounted for, the partial correlation between the import and the export tariffs used is 0.17 .
} 
by Proposition 2.b) and a positive sign for export tariff (as predicted by Proposition 3), but only the export tariff is statistically significant. The null hypothesis of both tariff coefficients being equal to zero is rejected at the $1 \%$ level. The 2 SLS estimated coefficients in column (3) show a negative effect for the import tariff, which is statistically significant at the $10 \%$ level ( $p$-value of 0.071 ), and a positive effect for the export tariff, which is statistically significant at the $5 \%$ level. Exogeneity of the import tariff is rejected at the $5 \%$ level by the Hausman test. As discussed before, the OLS estimate was expected to be positively biased, and this is confirmed by my estimates. The null hypothesis that both coefficients are zero is rejected at the $1 \%$ level. These results suggest that a 10-percentage-point decrease in import tariffs increases the expected informality share by 0.92 percentage points, while a 10-percentage-point decrease in export tariffs reduces the informality share by 1.71 percentage points.

The excluded instrument (Colombian tariffs) is statistically significant at the $1 \%$ level in the first-stage regression. A major concern about 2SLS estimates is the weak instrument problem that leads to inconsistent estimates. This issue is addressed by first conducting a Kleibergen-Paap LM test. Its null hypothesis is that the included and excluded instrument matrix does not have full rank, and it is rejected at the $10 \%$ level with a $p$-value of 0.076 . The next test available is the Stock-Yogo test with a null hypothesis that the actual size of the 2SLS t-test (at the $5 \%$ level of significance) can be greater than $10 \% .{ }^{30}$ Its critical value is 16.38 , and the Kleibergen-Paap rK Wald F-statistic of 16.14 is very close to the critical value. Finally, following the procedure suggested by Stock et al. (2002), I also estimated column (4) specification using the following weak instrument partially robust estimators: Fuller- $k$, limited information maximum likelihood, and continuously updated generalized method of moments. The rationale is that these estimators have different distributions under weak instruments. Thus, if the excluded instrument is weak, these estimators will provide estimates that are very different from the 2SLS estimates. Fortunately, this is not the case in my estimations, in which estimates across those estimators are very close to the 2SLS estimates. In sum, these results suggest that my estimates are not plagued by the weak instrument problem.

The IVProbit estimated coefficients in column (4) have the same signs of column (3) specification, but only the export tariff is statistically significant. The null hypothesis that both tariff

\footnotetext{
${ }^{30}$ The Stock-Yogo test with the null hypothesis that the bias of the 2SLS, as a fraction of OLS bias, is greater than $10 \%$ cannot be performed here because the critical values cannot be calculated when there is only one excluded instrument.
} 
coefficients are zero is rejected at the $1 \%$ level. The marginal effects calculated at the average imply that a ten percentage point decrease in the import tariff increases the informality share by 3.77 percentage points, while a ten percentage point decrease in export tariffs reduces the informality share by 7 percentage points. The Wald exogeneity test does not reject the null hypothesis of exogeneity of the import tariff.

Although not reported in Table 4, the majority of worker characteristic variables are statistically significant, which means that workers' characteristics do matter for their job formality status. The other formal ${ }_{i j t}$ variable is negative as expected and statistically significant in columns (1)-(4). The specifications in columns (5) and (6) do not include the other formal ${ }_{i j t}$ variable, and they provide similar estimates for the import and export tariff coefficients.

Almeida and Carneiro (2012) suggest that the enforcement of labor regulation varies by year and Brazilian state. To account for that, I add state-by-year fixed effects in equation (16) and reestimate Table 4 columns (3) and (4) specifications. The results are reported on Table 4 columns (7) and (8). The 2SLS specification in column (7) have the same signs as columns (3)specification, but now both import and export tariffs are statistically significant at the $10 \%$ level. the import tariff coefficient became larger in magnitude while the export tariff decreased in magnitude. A pattern similar to column (4) shows up in the IVProbit estimates in column (8). The remaining test results are very similar.

In Table 5, I address the industry-year serial correlation issue by clustering the standard error at the industry level. We can see in columns (1) and (3) that the import tariff coefficient is now statistically significant at the $5 \%$ level in the 2SLS specification. The coefficient of the export tariff on the 2SLS specification is significant at the $10 \%$ level when state-by-year effects are not used. But when state-by-year effects are included in the specification, the export tariff coefficient exhibits a $p$-value close to $10 \%$ which is still not statistically significant at the $10 \%$ level. Nonetheless, the null hypothesis that both import and export tariff coefficients are zero is rejected at the $5 \%$ level.

Though not contemplated in the theoretical model, I assess the effects of intermediate inputs on informality. To do so, I replace the import tariff by the ERP. ${ }^{31}$ The results are reported in Table 5 columns (5) and (6), and are very similar to the results in Table 4 columns (3) and (4),

\footnotetext{
${ }^{31} \mathrm{My}$ data has only 15 industries. This implies that an input tariff variable would be highly correlated with output import tariffs, making it very hard to identify separately the effects of both. A solution is to employ the effective rate of protection.
} 
except that in the 2SLS specification, column (5), the export tariff coefficient is now statistically significant at the $10 \%$ level. A comparison with prior studies using Brazilian data will be presented in the robustness subsection, where I conduct estimates using specifications that are closely related to those previously used in the literature. Now, I turn to the predictions regarding the average formal and informal wages.

\subsection{Formal and Informal Average Wages}

To assess the effects of import and export tariffs on formal average wages, I first estimate equation (17) for formal workers and equation (18) for informal workers. The first identification case considered has the inverse Mills ratio calculated using the predicted values from the IVProbit model (as in column (4) of Table 4 and column (4) of Table 5), which includes the other formal ijt $_{\text {variable, a }}$ variable not present in the wage equations. The results for average formal and informal wage are reported in Tables 6 and 7 , respectively.

In Table 6, the 2SLS estimates are presented in columns (1) and (3), where the latter specification includes state-by-year effects. These estimates exhibit a positive import tariff coefficient and a negative export tariff coefficient. Only the export tariff coefficient is statistically significant, but the null hypothesis that both coefficients are zero is rejected at the $5 \%$ level for both specifications. Since the null hypothesis of exogeneity of the import tariff is not rejected at the $5 \%$ level, I also estimate both specifications of the formal wage equation by OLS, as shown in columns (2) and (4). Again, the estimated import tariff coefficient is positive and the export tariff coefficient is negative, but now both are statistically significant. Using column (2) estimates, I compute the marginal effects at the average value of workers' characteristics $\left(\right.$ in $\left.\widehat{\text { form }} a l_{i j t}^{*}=-1.0873\right)$. The results indicate that a percentage point decrease in the export tariff increases the formal wage by $0.32 \%$, whereas a percentage point decrease in the import tariff decreases the formal wage by $0.05 \%$. In particular, the coefficients decrease in absolute value and do not change signs as inform $_{\text {fol }}^{*}{ }_{\text {ijt }}$ approaches zero, which further corroborates Propositions 4 and 5. In all Table 6 estimates, the inverse Mills ratio is statistically significant, which highlights the importance of controlling for self-selection into informal jobs when assessing the effect of tariffs on wages.

For the average informal wage, column (1) in Table 7 reports the 2SLS estimates for the specification without state-by-year effects. These results indicate that neither the import nor export 
tariffs are statistically significant. The null hypothesis that both tariff coefficients are equal to zero cannot be rejected at the $10 \%$ level. The null hypothesis of exogeneity of the import tariff is not rejected at the $5 \%$ level. This motivates the OLS estimates that are presented in column (2), where both coefficients remain positive. The export tariff coefficient is still not statistically significant, but the import tariff is now statistically significant at the $10 \%$ level. The null hypothesis that both coefficients are equal to zero is not rejected at the $5 \%$ level.

Columns (3) and (4) report the 2SLS and OLS estimates for the specification with state-by-year effects, respectively. For both estimators, the import tariff coefficient is positive and statistically significant at the $10 \%$ level; however, the export tariff coefficient has the opposite sign of columns' (1) and (2) specification. It is negative and not statistically significant. The null hypothesis of exogeneity of import tariffs cannot be rejected either. And the null hypothesis of the joint test of significance cannot be rejected at the $5 \%$ level for columns (3) and (4). Finally, in all Table 7 estimates, the inverse Mills ratio is again statistically significant, which underscores the importance of controlling for self-selection into informal jobs when assessing the effect of tariffs on wages.

In the second identification case, the inverse Mills ratio is now calculated using the predicted values of the IVProbit specifications that do not include the otherformal ${ }_{i j t}$ variable. So, the identification now comes through the IVProbit's non-linearity. I re-estimate the wage equations (17) and (18), and present the results for the average formal and informal wages in Tables 8 and 9, respectively. The results in Table 8 are very similar to those in Table 6 , with the qualification that the estimated coefficients in Table 8 are slightly larger in magnitude and are statistically significant at the $5 \%$ level.

The estimates in Table 9 differ from those in Table 7 . In the specifications without state-by-year effects, columns (1) and (2), the export tariff coefficient is positive, statistically significant at the $5 \%$ level, and larger than the coefficient in Table 7 column (2), while the import tariff is negative and statistically significant only in the OLS estimate, column (2), and at the $10 \%$ level. The null hypothesis of exogeneity of the import tariff is not rejected at the $5 \%$ level. The specifications with state-by-year effects, columns (3) and (4), also exhibit a positive and statistically significant coefficient for the export tariff. The import tariff is not statistically significant and is positive in the 2SLS specification, column (3), and negative in the OLS specification, column (4). The null hypothesis of exogeneity of the import tariff is not rejected at the $5 \%$ level either. 
So far, my empirical results mildly support Proposition 2.b to the detriment of Proposition 2.a, and strongly corroborate the predictions of Propositions 3, 4, and 5. The theoretical model's predictions about the average informal wage were ambiguous. The same picture emerged from the empirical results since they were heavily dependent upon the econometric specification used.

\subsection{Robustness Checks}

Several robustness checks were undertaken to investigate the sensitivity of the previous results to a different definition of informality, the omission of the export tariff, any pre-existing trends in the data, outliers, the construction of the export tariff variable, and the way in which worker characteristics enter the econometric specifications.

The first robustness exercise consists of using my sample and adopting a different definition of informality, in which an informal worker does not have a signed labor contract. The estimates are displayed in columns (1) and (2) of Table 10, and these results are very similar to those in Table 4 for the export tariff while the import tariff coefficient was not statistically significant at the $10 \%$ level. Furthermore, in the 2SLS specification, column (2), the null of the joint significance test could not be rejected at the $5 \%$ level.

Because the role of exports is usually ignored in the literature (see, e.g., Goldberg and Pavcnik, 2003), I conduct a second robustness exercise in which I re-estimate the specifications in Table 4 columns (1)-(4) without the export tariff variable. The results are presented in Table 10. The import tariff estimated coefficient is not statistically significant in all specifications. It is positive in columns (3), (4), and (6) and negative only in the 2SLS specification, column (5), which exhibited a coefficient that is much smaller in magnitude than the coefficient of Table 4 column (3). The null hypothesis of exogeneity of the import tariff is not rejected for the 2SLS and the IVProbit specifications.

The specification in column (3) of Table 10 is the closest to the empirical models used by the other studies using Brazilian data. Column (3) results indicate no impact of tariffs on informality share. As the endogeneity of tariffs is addressed in column (4), the coefficient's sign switches but its magnitude remains small. Thus, despite the differences in data construction, a plausible explanation for why the results in Table 4 differ from the results in Goldberg and Pavcnik (2003), MenezesFilho and Muendler (2011), and Bosch et al. (2007) is that they do not address the endogeneity 
of import tariffs and omit the role of export tariffs. Moreover, according to Bosch et al. (2007) changes in labor regulations (the 1988 Constitution) enacted before the trade liberalization that affected equally all sectors of the economy are behind the changes in the informality. Nevertheless, Figure 1 demonstrates that the share of informal workers in the services sector remained almost constant over the years.

Next, in order to investigate the consequences of omitting the export tariff variable in the wage equations (17) and (18), I calculate the inverse Mills ratio, using the IVProbit estimates in Table 10 column (6), and then estimate the wage equations. The results are presented in Table 11. Column (1) presents the 2SLS estimate of the formal wage equation. The import tariff coefficient is negative and statistically significant at the $5 \%$ level, which is the opposite of the results in Tables 6 and 8 . The null hypothesis of exogeneity of the import tariff is rejected at the $1 \%$ level in the Hausman test. In the OLS estimates, column (2), the estimated coefficient for import tariff is also negative and statistically significant. For the informal average wage, columns (3) and (4), both the 2SLS and the OLS estimates exhibit positive and statistically significant coefficients for the import tariff, as in Table 7 but contrary to the results in Table 9 . The null hypothesis of exogeneity of the import tariff is not rejected for column (3) specification. Hence, the export tariff omission leads to biased estimates of the effect of import tariffs.

Third, to check for pre-existing trends that may be driving the results, I conduct a placebotype test that consists of replacing the 1989-2001 worker-level data with the 1981-1993 worker-level data while still using the 1989-2001 tariff data. Then, I re-estimate the specifications from Table 4 columns (1)-(4). The results are presented in Table 12. If the results in Table 4 are driven by pre-existing trends in the data, then the tariff coefficients in Table 12 will be statistically significant. I found that the results do not support the hypothesis of pre-existing trends. Except for the export tariff coefficient that is statistically significant at the $5 \%$ level in the Probit specification, column (2); however, for all of the specifications in Table 12, the null hypothesis that both import and export tariff coefficients are zero cannot be rejected at the $5 \%$ level.

The fourth robustness exercise checked whether the results were driven by outliers. To do this, the tariff variables are replaced by $\log (1+$ tariff $)$, because this nonlinear and monotonic transformation reduces the influence of large values in the estimates. The new results are very similar to the previous estimates and thus are omitted here. 
The fifth robustness check consists of excluding Argentinean data from the export tariff construction. The reason for conducting this test is that Argentina's import tariff that is applied to Brazilian goods may not be exogenous because the Mercosur Customs Unions internal tariffs were negotiated among its members. To address this concern, I recalculated the export tariff variable

without Argentina's tariffs, and then re-estimated the specifications in Tables 4, 5, 6, and 7. The resulting estimates were similar and thus are omitted.

A sixth robustness check entails replacing the variables involving age and education with a set of dummies for age ranges and education achievements in order to address the concern that nonlinearity in the returns to education and experience may affect the tariffs' estimated coefficients. The specifications in Tables 4, 5, 6, and 7 are re-estimated and the results are similar. Therefore, they are omitted.

\section{Conclusions}

This paper sheds some light on the important issue of the impacts of trade liberalization on labor markets by presenting a novel theoretical model of a small open economy in which trade policy affects firms' payroll tax compliance - the major determinant of whether jobs are formal or informal. The theoretical model predicts that a decrease in the Home import tariff can increase or reduce the Home share of informal workers depending on the initial labor market conditions, while Foreign import tariff cuts decrease the share of informal workers. In addition, the model predicts that a reduction in the Home import tariff decreases the average formal wage, whereas a decrease in the Foreign import tariff increases the average formal wage. No prediction regarding the average informal wage can be derived unless the model is fully parametrized.

Next, I assess the theoretical model testable predictions using data from the Brazilian trade liberalization episode (1989-2001). My preferred estimates for the informality share (Table 4 column (3)) indicate that a percentage point decrease in import tariffs increases the informality share by 0.092 percentage points. Since some of these estimates are only statistically significant at the $10 \%$ level, they provide a mild support to Proposition 2.b. A similar change in foreign import tariffs decreases the informality share by 0.171 percentage points, which strongly corroborates Proposition 3. In addition, when the export tariff variable is omitted, the estimates of the import 
tariff's effect on the informality share become statistically insignificant, a result commonly found in the literature. Another important finding of the analysis is that addressing payroll tax enforcement makes a difference. The inclusion of state-by-year effects to account for heterogeneous enforcement led to estimated coefficients of a larger magnitude. Furthermore, the endogeneity of the import tariff is corroborated by the Hausman test results. These key aspects may explain the different results obtained by previous studies.

Evaluating the estimated effect of trade policy on informality share at the average change in import tariffs of -54 percentage points, and at the average change in export tariffs of -12 percentage points, leads to an expected increase in the manufacturing informality share of about three percentage points in Brazil, which is slightly more than one-third of the observed change of 8.4 percentage points.

For the average formal wage, the results support both Propositions 4 and 5. For the average worker, a percentage point decrease in import tariffs increases the average informal wage by $0.06 \%$, and decreases the average formal wage by $0.05 \%$. A similar change in foreign import tariffs decreases the average informal wage by $0.34 \%$, and increases the average formal wage by $0.32 \%$. Thus, for the average worker, the overall effect of trade policy reforms on the average informal wage is a 0.1 percentage point decrease and on the average formal wage is a 1.15 percentage point increase, leading to a widening of the formal-informal wage gap in Brazil. The magnitudes of these effects are inversely related to the likelihood of having an informal job, which means that although multilateral trade liberalization may reduce informality and increase the average wage, the benefits from trade liberalization are not the same for all workers. Finally, I find that not controlling for self-selection into informal jobs when estimating the effect of tariffs on wages can seriously bias the estimates.

A striking finding of this paper is that access to markets in developed countries can indeed be a market solution for labor informality in developing countries. Thus, an important avenue for future research is to investigate the optimal payroll tax in an open economy with endogenous compliance.

\section{Acknowledgments}

I would like to thank Nuno Limão for his guidance, and Gordon Hanson, Michael Kremer, Honório Kume, Derek Laing, Marc Melitz, Devashish Mitra, Emanuel Ornelas, Robert Staiger, and two 
anonymous referees for their insightful suggestions that led to significant improvements in this paper. Thanks are also due to seminar participants at the NEUDC conference and the Midwest International Trade meeting. Any remaining errors are my own.

\section{References}

Abowd, J. M., Kramarz, F. and D. N. Margolis (1999). High-wage Workers and High-wage Firms. Econometrica, 67, p. 251-333.

Abreu, M. (1996). Trade in manufactures: the outcome of the Uruguay Round and developing countries interests. In Martin, W. and L. A. Winters (eds.) "The Uruguay Round and the developing countries".

Acosta, P. and G. Montes-Rojas (2010). Informal Jobs and Trade Liberalization in Argentina. Mimeo.

AEPS (2005). Anuário Estatístico da Previdencia Social, Suplemento Histórico 2005. Ministério da Previdencia, Brasil.

Alm, J., McClelland, G. H., and W. D. Schulze (1992). Why do people pay taxes? Journal of Public Economics, 48(1), p. 21-38.

Alemán-Castilla, B. (2006). The Effect of Trade Liberalization on Informality and Wages: Evidence from Mexico. CEP Discussion Paper No. 763.

Almeida, R. and P. Carneiro (2012). Enforcement of Labor Regulations and Informality. American Economic Journal: Applied Economics, 4(3), 64-89.

Amemiya, T. (1985). Advanced Econometrics. Cambridge, MA: Harvard University Press.

Amiti, M. and D. Davis (2012). Trade, Firms, and Wages: Theory and Evidence. Review of Economic Studies, 79(1), 1-36.

Angrist, J. and J. Pischke (2008). Mostly Harmless Econometrics: An Empiricist's Companion. Princeton University Press. 
Bacchetta, M., Ernst, E. and J. Bustamante (2009). Globalization and Informal jobs in Developing Countries: A joint study of the International Labour Office and the Secretariat of the World Trade Organization. Geneva, Switzerland: WTO Publications.

Bertrand, M., Duflo, E., and S. Mullainathan (2004). How Much Should We Trust Differences-inDifferences Estimates? Quarterly Journal of Economics, 119, p. 249-275.

Boisvert, H., Bernard, R. and A. Queirz (2001). Benchmarking da funo finanas: uma anlise comparativa do custeio da folha de pagamento. Mimeo.

Bosch, M., Goni, E., and W. Maloney (2007). The Determinants of Rising Informality in Brazil: Evidence from Gross Worker Flows. IZA Discussion Papers 2970.

Broda, C., Limo N., and D. Weinstein (2008). Optimal Tariffs and Market Power: The Evidence. American Economic Review, 98(5), p. 2032-2065.

Cameron, A., Gelbach, J., and D. Miller (2008). Bootstrap-Based Improvements for Inference with Clustered Errors. Review of Economics and Statistics, 90(3), p. 414-427.

Cameron, A. and P. Trivedi (2005). Microeconometrics: Methods and Applications. New York, NY. Cambridge University Press.

Dasgupta, P. and D. Ray (1986). Inequality as a Determinant of Malnutrition and unemployment: theory. Economic Journal, 96, p. 1011-1034.

Davies, R. and L. Paz (2011). Tariffs versus VAT in the presence of heterogeneous firms and an informal sector. International Tax and Public Finance, 18(5), p. 533-554.

Davis, D. and J. Harrigan (2011). Good Jobs, Bad Jobs, and Trade Liberalization. Journal of International Economics, 84, p. 26-36.

Demidova, S. and A. Rodriguez-Clare (2011). The simple analytics of the Melitz Model in a small open economy. NBER Working paper 17521.

Ellery, R. G. and V. Gomes (2007). Exports, Productivity and Firms Size in Brazil. Revista Brasileira de Economia, 61(1), p. 33-48. 
Evans, C. (2003). Studying the Studies: An overview of recent research into taxation operating costs. Journal of Tax Research, 1, p. 64-92.

Feenstra, R., Romalis, J., and P. Schott (2002). U.S. Imports, Exports and Tariff Data, 1989-2001, NBER Working Paper 9387.

Finger, J. M. and L. Schuknecht (1999). Market Access Advances and Retreats Since the Uruguay Round Agreement. Annual World Bank Conference on Development Economics. Washington, DC.

Freund, C., Ornelas, E., and A. Estevadeordal (2008). Does Regionalism Affect Trade Liberalization towards Non-Members? Quarterly Journal of Economics, 123(4), p. 1531-1575.

Frias, J., Kaplan, D., and E. Verhoogen (2009). Exports and Wage Premia: Evidence from Mexican Employer-Employee Data. Mimeo.

Goldberg, P. and N. Pavcnik (2003). The Response of the Informal Sector to Trade Liberalization, Journal of Development Economics, 72, p. 463-496.

Goldberg, P. and N. Pavcnik (2005). Trade, Wages, and the Political Economy of Trade Protection: Evidence from the Colombian Trade Reforms. Journal of International Economics, 66(1), p. 75105.

Gruber, J. (1997). The Incidence of Payroll Taxation: Evidence from Chile. Journal of Labor Economics, 15 (3), p. S72-S101.

Hanson, G. and A. Harrison (1999). Who gains from trade reform? Some remaining puzzles. Journal of Development Economics, 59, p. 125-154.

Helpman, E. and O. Itskhoki. (2010). Labor Market Rigidities, Trade and Unemployment. Review of Economic Studies, 77 (3), p. 1100-1137.

Helpman, E., Itskhoki, O., and S. Redding (2008). Wages, Unemployment and Inequality with Heterogeneous Firms and Workers. NBER Working Paper 14122.

Hummels, D. (2001). Toward a Geography of Trade Costs. Purdue University, Mimeo.

IBGE (2011). Sistema IBGE de Recuperao Automtica - SIDRA. http://www.sidra.ibge.gov.br/. 
ILO (2001). Decent work and informal economy. Report VI. International Labour Conference, 90th Session. Geneva: International Labour Office.

Karacaovali, B., (2011). Productivity Matters for Trade Policy: Theory and Evidence. International Economic Review, 52, p. 33-62.

Keen, M. (2008). VAT, tariffs, and withholding: Border taxes and informality in developing countries. Journal of Public Economics, 92(10-11), p. 1892-1906.

Kézdi, G. (2004). Robust Standard Error Estimation in Fixed-Effects Panel Models, Hungarian Statistical Review, Special English Volume, 9, p. 95-116.

Kreickemeier, U. and H. Egger (2009). Firm Heterogeneity and the Labor Market Effects of Trade Liberalization. International Economic Review, 50, p. 187-216.

Krishna, P., Poole, J., and M. Senses (2011) Wage Effects of Trade Reform with Endogenous Worker Mobility. NBER Working Paper 17256.

Kovak, B. (2013). Local Labor Market Effects of Trade Policy: Evidence from Brazilian Liberalization. American Economic Review, forthcoming.

Kugler, A. (1999). The Impact of Firing Costs on Turnover and Unemployment: Evidence from the Colombian Labor Market Reform. International Tax and Public Finance Journal, 6, p. 389-410.

Kugler, A. (2011). Is There an Anti-Labor Bias of Taxes? A Survey of the Evidence from Latin America and Around the World. IDB Working Paper No. IDB-TN-299.

Kugler, A. and M. Kugler (2009). Labor Market Effects of Payroll Taxes in Developing Countries: Evidence from Colombia. Economic Development and Cultural Change, 57, p. 335-358.

Kume, H., Piani, G., and P. Miranda (2008). Política Comercial, Instituições e Crescimento Economico no Brasil. In: Kume, H. (ed.). "Crecimiento económico, instituciones, política comercial y defensa de la competencia en el MERCOSUR". Montevidu: Red Mercosur. Volume 11.

Kume, H., Piani, G., and C. F. Souza (2003). Instrumentos de Politica Comercial no Periodo 19871998. In Corseuil, C. H. and H. Kume (eds.) "A abertura comercial brasileira nos anos 1990: impactos sobre emprego e salário". Rio de Janeiro: Ipea. 
Kumler, T., Verhoogen, E., and J. Fras (2012). Enlisting Workers in Monitoring Firms: Payroll Tax Compliance in Mexico. Mimeo.

Liftschitz, E. (1991). Cálculo de los niveles de protección efectiva legal de los sectores productors de bienes 1990-1991. Documento de trabajo del proyecto: Competitividad e Integración Internacional de la economia Argentina, SIC-PNUD ARG.86-R01, Abril.

Maddala, G. S. (1983). Limited-Dependent and Qualitative Variables in Economics. Cambridge, UK: Cambridge University Press.

Mao, J., Zhang, L. and Z. Jing (2012). Social Security Taxation and Compliance: The Chinese Evidence. SSRN Working Paper 2151695.

McCaig, B. and N. Pavcnik (2012). Export Markets and Labor Reallocation: Evidence from the U.S.-Vietnam Bilateral Trade Agreement. Mimeo.

Melitz, M. (2003). The Impact of Trade on Intra-Industry Reallocations and Aggregate Industry Productivity. Econometrica 71 (6), p. 1695-1725.

Menezes-Filho, N. and M. Muendler (2011). Labor Reallocation in Response to Trade Reform. unpublished manuscript.

Minnesota Population Center (2007). Integrated Public Use Microdata Series - International: Version 3.0. Minneapolis: University of Minnesota.

Munk, K. (2008). Tax-tariff reform with costs of tax administration. International Tax and Public Finance, 15, p. 647-667.

Neri, M. (2002). Decent Work and the Informal Sector in Brazil. Ensaios Economicos EPGE n. 461.

Nicita, A. and M. Olarreaga (2006). Trade, Production and Protection 1976-2004. Mimeo.

Office of the United States Trade Representative (2007). Peru TPA Facts: Real Results on Labor Rights.

Office of the United States Trade Representative (2011). Colombian Action Plan Related to Labor Rights. 
Pavcnik, N., Blom, A., Goldberg, P., and N. Schady (2004). Trade Liberalization and Industry Wage Structure: Evidence from Brazil. World Bank Economic Review, 18(3), p. 319-344.

Perry, G., Maloney, W., Arias, O., Fajnzylber, P., Mason, A., and J. Saavedra-Chanduvi (2007). Informality: Exit and Exclusion. World Bank Latin American and Caribbean Studies. Washington, D.C.: The World Bank.

Portes, A., Castells, M., and L. Benton (1989). World Underneath: The Origins, Dynamics and Effects of the Informal Economy. The Informal Economy: Studies in Advanced and Less-Developed Countries. Eds. A. Portes, M. Castells, and L. Brenton. Baltimore and London: The John Hopkins University Press.

Pratap, S. and E. Quintin (2006). Are labor markets segmented in developing countries? A semiparametric approach. European Economic Review, 50, p. 1817-1841.

Ray, D. (1998). Development Economics. Princeton University Press.

Roberts, B. (1989). "Employment Structure, Life Cycle, and Life Changes: Formal and Informal Sectors in Guadalajara" in The Informal Economy: Studies in Advanced and Less Developed Countries, ed. by A. Portes, M. Castells, and L. A. Breton. Baltimore and London: The John Hopkins University Press.

Rodrik, D. (1992). The Limits of Trade Policy Reform in Developing Countries. Journal of Economic Perspective, 6(1), p. 87-105.

Romalis, J. (2007). NAFTA'S and CUSFTA's Impact on International Trade. Review of Economics and Statistics, 89(3), p. 416-435.

Schank, T., Schnable, C., and J. Wagner (2007). Do exporters really pay higher wages? First evidence from German linked employer-employee data. Journal of International Economics, 72, $52-74$.

Schmidt, C. and K. Zimmermann (1991). Work Characteristics, Firm Size and Wages. Review of Economics and Statistics, 73(4), p. 705-710. 
Schneider, F. and D. Enste (2000). Shadow Economies: Size, Causes, and Consequences. Journal of Economic Literature, 38, p. 77-114.

Schor, A. (2004). Heterogeneous Productivity Response to Tariff Reduction: Evidence from Brazilian Manufacturing Firms. Journal of Development Economics, 75(2), 373-96.

Shapiro, C. and J. Stiglitz (1984). Equilibrium Unemployment as a Worker Discipline Device. American Economic Review, 74(3), p. 433-444.

Stock, J. H., Wright, J. H., and M. Yogo (2002). A survey of weak instruments and weak identification in generalized method of moments. Journal of Business and Economic Statistics, 20, $518-529$. 
Table 1 - Descriptive statistics of worker characteristics in Brazil by industry.

\begin{tabular}{|c|c|c|c|c|c|c|c|c|c|c|}
\hline \multirow[b]{2}{*}{ Industry } & \multicolumn{4}{|c|}{ Share of informal workers } & \multicolumn{3}{|c|}{ Average informal worker characteristics } & \multicolumn{3}{|c|}{ Average formal worker characteristics } \\
\hline & Average & Std. dev. & Min & $\operatorname{Max}$ & Education & Age & Share of males & Education & Age & Share of males \\
\hline Nonmetallic mineral products & 0.288 & 0.027 & 0.242 & 0.344 & 4.10 & 27.03 & 0.92 & 5.97 & 32.45 & 0.88 \\
\hline Metals production and processing & 0.122 & 0.050 & 0.063 & 0.205 & 6.12 & 28.49 & 0.92 & 7.25 & 33.05 & 0.89 \\
\hline $\begin{array}{l}\text { Machinery, equipment and } \\
\text { commercial installation }\end{array}$ & 0.078 & 0.040 & 0.034 & 0.153 & 6.76 & 31.11 & 0.79 & 7.81 & 33.39 & 0.86 \\
\hline $\begin{array}{l}\text { Electrical and electronic } \\
\text { equipment }\end{array}$ & 0.070 & 0.037 & 0.027 & 0.124 & 7.96 & 26.89 & 0.75 & 8.53 & 31.03 & 0.71 \\
\hline Automobile, truck and bus & 0.056 & 0.023 & 0.032 & 0.104 & 6.92 & 31.16 & 0.83 & 7.85 & 33.51 & 0.87 \\
\hline Wood sawing and wood products & 0.325 & 0.063 & 0.239 & 0.424 & 5.00 & 27.94 & 0.94 & 5.60 & 31.64 & 0.87 \\
\hline $\begin{array}{l}\text { Pulp and paper production, paper } \\
\text { products, printing and publishing }\end{array}$ & 0.134 & 0.048 & 0.062 & 0.208 & 7.80 & 28.54 & 0.70 & 8.16 & 31.66 & 0.76 \\
\hline Rubber products & 0.071 & 0.037 & 0.012 & 0.153 & 6.37 & 30.01 & 0.76 & 7.11 & 32.56 & 0.85 \\
\hline $\begin{array}{l}\text { Chemicals and fertilizer (excludes } \\
\text { petrochemicals) }\end{array}$ & 0.072 & 0.016 & 0.048 & 0.110 & 5.79 & 30.26 & 0.71 & 7.66 & 33.70 & 0.81 \\
\hline $\begin{array}{l}\text { Pharmaceutical, perfumes, } \\
\text { detergents and candles }\end{array}$ & 0.103 & 0.028 & 0.063 & 0.181 & 8.23 & 30.64 & 0.56 & 9.02 & 32.13 & 0.62 \\
\hline Plastics products & 0.094 & 0.028 & 0.047 & 0.148 & 6.39 & 29.05 & 0.69 & 7.05 & 31.30 & 0.66 \\
\hline Textiles & 0.104 & 0.030 & 0.055 & 0.187 & 5.71 & 29.71 & 0.47 & 6.66 & 31.34 & 0.59 \\
\hline Apparel & 0.260 & 0.040 & 0.186 & 0.335 & 6.19 & 30.72 & 0.19 & 6.68 & 31.11 & 0.22 \\
\hline Footwear and leather products & 0.181 & 0.030 & 0.115 & 0.233 & 5.62 & 29.45 & 0.47 & 6.16 & 28.87 & 0.57 \\
\hline $\begin{array}{l}\text { Coffee, food, beverages, animal } \\
\text { feed and tobacco }\end{array}$ & 0.181 & 0.029 & 0.140 & 0.222 & 5.17 & 27.80 & 0.70 & 6.51 & 32.00 & 0.74 \\
\hline
\end{tabular}

Source: Brazilian PNAD data. Notes: Sample weights used. An informal worker is one whose employer does not comply with payroll taxes. The average characteristics of formal and informal workers are all statistically different from each other. 
Table 2 - Employment shares in Brazil, by firm employment level and formality status.

\begin{tabular}{|c|c|c|c|c|}
\hline \multirow[b]{3}{*}{$\begin{array}{l}\text { Number of } \\
\text { employees }\end{array}$} & \multicolumn{4}{|c|}{ Year } \\
\hline & \multicolumn{2}{|c|}{1989} & \multicolumn{2}{|c|}{1999} \\
\hline & $\begin{array}{c}\text { Formal } \\
\text { share }\end{array}$ & $\begin{array}{c}\text { Informal } \\
\text { share }\end{array}$ & $\begin{array}{c}\text { Formal } \\
\text { share }\end{array}$ & $\begin{array}{c}\text { Informal } \\
\text { share }\end{array}$ \\
\hline 2 & 0.20 & 0.83 & 0.45 & 1.50 \\
\hline 3 to 5 & 2.27 & 3.41 & 3.33 & 5.82 \\
\hline 6 to 10 & 3.21 & 2.05 & 6.17 & 4.19 \\
\hline 11 or more & 82.05 & 5.97 & 69.50 & 9.04 \\
\hline
\end{tabular}

Source: Brazilian 1989 and 1999 PNAD data.

Notes: An informal worker is one whose employer does not comply with payroll taxes. The data is presented at the most disaggregated level available. The question about firm employment level is included in the PNAD survey only in selected years. 
Table 3 - Descriptive statistics of industry-level tariffs in Brazil, Brazil Trade Partners, and Colombia 1989-2001.

Industry

Brazilian Import Tariff $\quad$ Brazil's Trade Partners' Imp. Tariff

Colombian Import Tariff

\begin{tabular}{|c|c|c|c|c|c|c|c|c|c|c|c|c|c|}
\hline Code & Description & Average & dev & Min & $\operatorname{Max}$ & Average & dev & Min & Max & Average & dev & Min & $\operatorname{Max}$ \\
\hline 4 & Nonmetallic mineral products & 0.194 & 0.145 & 0.092 & 0.638 & 0.114 & 0.047 & 0.057 & 0.173 & 0.257 & 0.123 & 0.131 & 0.485 \\
\hline 567 & Metals production and processing & 0.150 & 0.077 & 0.080 & 0.360 & 0.072 & 0.032 & 0.036 & 0.117 & 0.193 & 0.099 & 0.098 & 0.391 \\
\hline 8 & $\begin{array}{l}\text { Machinery, equipment and } \\
\text { commercial installation }\end{array}$ & 0.229 & 0.123 & 0.116 & 0.490 & 0.071 & 0.032 & 0.038 & 0.120 & 0.142 & 0.070 & 0.065 & 0.306 \\
\hline 1011 & Electrical and electronic equipment & 0.259 & 0.142 & 0.133 & 0.607 & 0.091 & 0.040 & 0.045 & 0.150 & 0.247 & 0.148 & 0.114 & 0.569 \\
\hline 1213 & Automobile, truck and bus & 0.382 & 0.181 & 0.191 & 0.848 & 0.107 & 0.049 & 0.055 & 0.217 & 0.229 & 0.124 & 0.113 & 0.491 \\
\hline 14 & Wood sawing and wood products & 0.172 & 0.105 & 0.088 & 0.500 & 0.118 & 0.056 & 0.051 & 0.188 & 0.340 & 0.184 & 0.167 & 0.732 \\
\hline 15 & $\begin{array}{l}\text { Pulp and paper production, paper } \\
\text { products, printing and publishing }\end{array}$ & 0.174 & 0.125 & 0.083 & 0.595 & 0.072 & 0.032 & 0.034 & 0.115 & 0.263 & 0.129 & 0.128 & 0.468 \\
\hline 16 & Rubber products & 0.255 & 0.198 & 0.121 & 0.820 & 0.092 & 0.038 & 0.048 & 0.144 & 0.234 & 0.098 & 0.136 & 0.430 \\
\hline 1719 & $\begin{array}{l}\text { Chemicals and fertilizer (excludes } \\
\text { petrochemicals) }\end{array}$ & 0.169 & 0.099 & 0.070 & 0.451 & 0.076 & 0.027 & 0.042 & 0.118 & 0.138 & 0.070 & 0.066 & 0.272 \\
\hline 20 & $\begin{array}{l}\text { Pharmaceutical, perfumes, } \\
\text { detergents and candles }\end{array}$ & 0.186 & 0.179 & 0.046 & 0.723 & 0.098 & 0.049 & 0.045 & 0.172 & 0.218 & 0.110 & 0.106 & 0.397 \\
\hline 21 & Plastics products & 0.249 & 0.144 & 0.151 & 0.571 & 0.129 & 0.051 & 0.073 & 0.204 & 0.378 & 0.210 & 0.179 & 0.800 \\
\hline 22 & Textiles & 0.275 & 0.201 & 0.132 & 0.874 & 0.161 & 0.061 & 0.084 & 0.249 & 0.418 & 0.264 & 0.182 & 1.023 \\
\hline 23 & Apparel & 0.362 & 0.255 & 0.194 & 1.027 & 0.212 & 0.076 & 0.122 & 0.317 & 0.479 & 0.316 & 0.198 & 1.199 \\
\hline 24 & Footwear and leather products & 0.232 & 0.154 & 0.132 & 0.741 & 0.188 & 0.063 & 0.109 & 0.259 & 0.358 & 0.206 & 0.157 & 0.757 \\
\hline 2531 & $\begin{array}{l}\text { Coffee, food, beverages, animal } \\
\text { feed and tobacco }\end{array}$ & 0.213 & 0.131 & 0.123 & 0.658 & 0.267 & 0.071 & 0.169 & 0.341 & 0.286 & 0.126 & 0.137 & 0.455 \\
\hline
\end{tabular}

Sources: Kume (2003), and others. Note: An import tariff of 0.20 represents a $20 \%$ tariff. 
Table 4 - Estimates of the effects of trade policy changes on the probability of a worker having an informal job.

\begin{tabular}{|c|c|c|c|c|c|c|c|c|}
\hline \multirow[b]{2}{*}{ Independent Variables / Technique } & \multicolumn{8}{|c|}{ Dependent Variable: informal job indicator } \\
\hline & $\begin{array}{l}(1) \\
\text { OLS }\end{array}$ & $\begin{array}{c}(2) \\
\text { Probit }\end{array}$ & $\begin{array}{c}(3) \\
\text { 2SLS }\end{array}$ & $\begin{array}{c}(4) \\
\text { IVProbit }\end{array}$ & $\begin{array}{c}(5) \\
2 S L S\end{array}$ & $\begin{array}{c}(6) \\
\text { IVProbit }\end{array}$ & $\begin{array}{c}(7) \\
2 S L S\end{array}$ & $\begin{array}{c}(8) \\
\text { IVProbit }\end{array}$ \\
\hline Import tariff & $\begin{array}{c}0.013 \\
(0.033)\end{array}$ & $\begin{array}{l}-0.012 \\
(0.127)\end{array}$ & $\begin{array}{l}-0.092^{*} \\
(0.051)\end{array}$ & $\begin{array}{l}-0.166 \\
(0.247)\end{array}$ & $\begin{array}{l}-0.103^{*} \\
(0.053)\end{array}$ & $\begin{array}{l}-0.189 \\
(0.252)\end{array}$ & $\begin{array}{l}-0.129 * \\
(0.071)\end{array}$ & $\begin{array}{l}-0.336 \\
(0.335)\end{array}$ \\
\hline Export tariff & $\begin{array}{c}0.117 \\
(0.076)\end{array}$ & $\begin{array}{c}1.517 * * * \\
(0.403)\end{array}$ & $\begin{array}{c}0.171 * * \\
(0.082)\end{array}$ & $\begin{array}{c}1.594 * * * \\
(0.429)\end{array}$ & $\begin{array}{l}0.166^{*} \\
(0.085)\end{array}$ & $\begin{array}{c}1.593 * * * \\
(0.439)\end{array}$ & $\begin{array}{l}0.151^{*} \\
(0.092)\end{array}$ & $\begin{array}{c}1.466 * * * \\
(0.449)\end{array}$ \\
\hline Another household member has a formal job & $\begin{array}{c}-0.069 * * * \\
(0.004) \\
\end{array}$ & $\begin{array}{c}-0.287 * * * \\
(0.015) \\
\end{array}$ & $\begin{array}{c}-0.069 * * * \\
(0.004) \\
\end{array}$ & $\begin{array}{c}-0.287 * * * \\
(0.015) \\
\end{array}$ & & & $\begin{array}{c}-0.067 * * * \\
(0.003) \\
\end{array}$ & $\begin{array}{c}-0.284^{* * * *} \\
(0.013) \\
\end{array}$ \\
\hline State-by-year indicators & No & No & No & No & No & No & Yes & Yes \\
\hline Observations & 775331 & 775331 & 775331 & 775331 & 775331 & 775331 & 775331 & 775331 \\
\hline $\begin{array}{l}\text { Under identification test (Kleibergen-Paap rk LM } \\
\text { statistic) }\end{array}$ & & & $\begin{array}{c}3.13^{*} \\
{[0.076]}\end{array}$ & & $\begin{array}{c}3.13^{*} \\
{[0.077]}\end{array}$ & & $\begin{array}{c}3.18^{*} \\
{[0.075]}\end{array}$ & \\
\hline $\begin{array}{l}\text { Weak identification test Kleibergen-Paap rk Wald F } \\
\text { statistic }\end{array}$ & & & 16.14 & & 16.14 & & 16.76 & \\
\hline Stock-Yogo test critical value for $10 \%$ max IV size & & & 16.38 & & 16.38 & & 16.38 & \\
\hline Endogeneity Test & & & $\begin{array}{c}4.244 * * \\
{[0.039]}\end{array}$ & & $\begin{array}{l}4.788^{* *} \\
{[0.0287]}\end{array}$ & & $\begin{array}{l}5.83 * * \\
{[0.016]}\end{array}$ & \\
\hline Wald Exogeneity test & & & & $\begin{array}{c}0.385 \\
{[0.535]}\end{array}$ & & $\begin{array}{c}0.51 \\
{[0.473]}\end{array}$ & & $\begin{array}{c}1.21 \\
{[0.271]}\end{array}$ \\
\hline Test of both Import tariff $=0$ and Export tariff $=0$ & $\begin{array}{c}1.27 \\
{[0.284]}\end{array}$ & $\begin{array}{c}14.45^{* * *} \\
{[0.001]}\end{array}$ & $\begin{array}{l}6.23 * * \\
{[0.044]}\end{array}$ & $\begin{array}{c}14.16^{* * * *} \\
{[0.008]}\end{array}$ & $\begin{array}{l}6.06^{* *} \\
{[0.048]}\end{array}$ & $\begin{array}{c}13.45^{* * * *} \\
{[0.001]}\end{array}$ & $\begin{array}{l}4.43 * * \\
{[0.010]}\end{array}$ & $\begin{array}{c}10.85^{* * *} \\
{[0.004]}\end{array}$ \\
\hline Estimated coefficients in the $1^{\text {st }}$ stage & & & & & & & & \\
\hline Colombian tariff (excluded instrument) & & & $\begin{array}{c}0.378 * * * \\
(0.094)\end{array}$ & $\begin{array}{c}0.378 * * * \\
(0.094)\end{array}$ & $\begin{array}{c}0.378^{* * *} \\
(0.094)\end{array}$ & $\begin{array}{c}0.378^{* * *} \\
(0.094)\end{array}$ & $\begin{array}{c}0.380^{* * *} \\
(0.093)\end{array}$ & $\begin{array}{c}0.380^{* * *} \\
(0.093)\end{array}$ \\
\hline Export tariff (included instrument) & & & $\begin{array}{l}-0.044 \\
(0.168) \\
\end{array}$ & $\begin{array}{l}-0.044 \\
(0.168) \\
\end{array}$ & $\begin{array}{l}-0.044 \\
(0.168)\end{array}$ & $\begin{array}{l}-0.044 \\
(0.168) \\
\end{array}$ & $\begin{array}{l}-0.195 \\
(0.160) \\
\end{array}$ & $\begin{array}{l}-0.195 \\
(0.160)\end{array}$ \\
\hline
\end{tabular}

Standard errors are clustered on industry by year reported in parentheses. *** p<0.01, ** p<0.05,* p<0.1; p-values reported in brackets. Year and industry effects,

worker characteristics, and a constant were included in every stage of all estimated models. Sample weights used. 
Table 5 - Estimates of the effects of trade policy changes on the probability of a worker having an informal job, using the effective rate of protection and standard levels clustered at industry level.

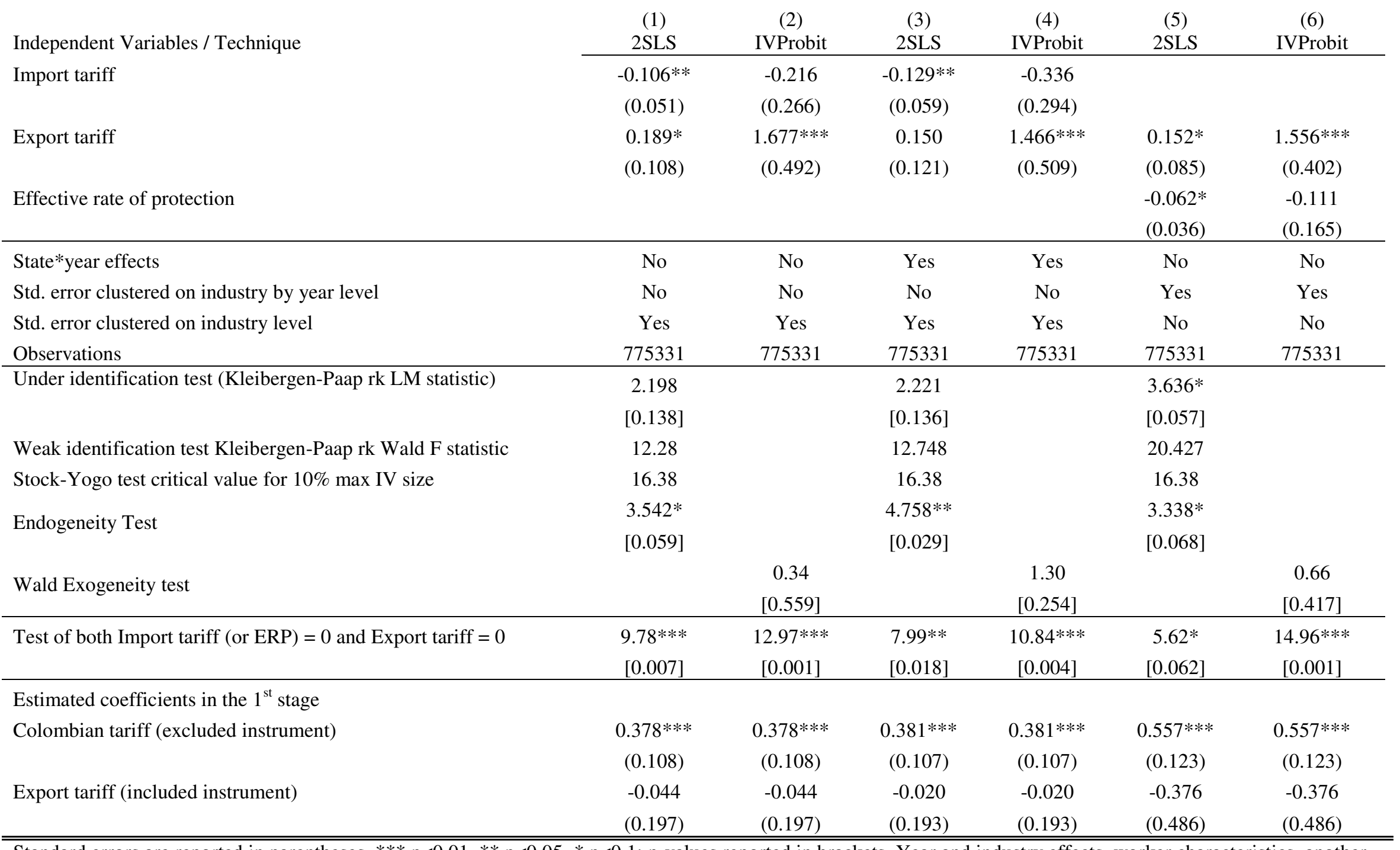

Standard errors are reported in parentheses. ${ }^{* * *} \mathrm{p}<0.01,{ }^{* *} \mathrm{p}<0.05,{ }^{*} \mathrm{p}<0.1 ; \mathrm{p}$-values reported in brackets. Year and industry effects, worker characteristics, another household member has a formal job indicator and a constant were included in every stage of all estimated models. Sample weights used. 
Table 6 - Estimates of the effects of trade policy changes on the average formal wages.

\begin{tabular}{|c|c|c|c|c|}
\hline & \multicolumn{4}{|c|}{ Formal Wage } \\
\hline & (1) & (2) & (3) & (4) \\
\hline & 2SLS & OLS & 2SLS & OLS \\
\hline $\begin{array}{l}\text { Independent Variables / Technique } \\
\text { Import tariff }\end{array}$ & $\begin{array}{c}0.026 \\
(0.051)\end{array}$ & $\begin{array}{c}0.086 * * * \\
(0.020)\end{array}$ & $\begin{array}{c}0.020 \\
(0.051)\end{array}$ & $0.046^{* *}$ \\
\hline Export tariff & $\begin{array}{c}-0.634 * * * \\
(0.056)\end{array}$ & $-0.663 * * *$ & $\begin{array}{c}-0.524 * * * \\
(0.051)\end{array}$ & $-0.538^{* * *}$ \\
\hline Inverse mills ratio & $\begin{array}{c}0.618 * * * \\
(0.012)\end{array}$ & $\begin{array}{c}0.619 * * * \\
(0.012)\end{array}$ & $\begin{array}{c}0.271^{* * *} \\
(0.011)\end{array}$ & $\begin{array}{c}0.271 * * * \\
(0.011)\end{array}$ \\
\hline $\begin{array}{l}\text { State*year effects } \\
\text { Observations }\end{array}$ & $\begin{array}{c}\text { No } \\
640183\end{array}$ & $\begin{array}{c}\text { No } \\
640183\end{array}$ & $\begin{array}{c}\text { Yes } \\
640183\end{array}$ & $\begin{array}{c}\text { Yes } \\
640183\end{array}$ \\
\hline Endogeneity Test & $\begin{array}{c}1.635 \\
{[0.201]}\end{array}$ & & $\begin{array}{c}1.443 \\
{[0.226]}\end{array}$ & \\
\hline Test of both Import tariff $=0$ and Export tariff $=0$ & $\begin{array}{c}206.68 * * * \\
{[0.000]}\end{array}$ & $\begin{array}{c}223.85 * * * \\
{[0.000]}\end{array}$ & $\begin{array}{c}25.00 * * * * \\
{[0.000]}\end{array}$ & $\begin{array}{c}16.75 * * * \\
{[0.000]}\end{array}$ \\
\hline \multicolumn{5}{|l|}{ Instruments (estimated coefficient in $1^{\text {st }}$ stage) } \\
\hline $\begin{array}{l}\text { Instruments (estimated coefficient in I"stage) } \\
\text { Colombian tariff }\end{array}$ & $\begin{array}{c}0.372 * * * \\
(0.001)\end{array}$ & & $\begin{array}{c}0.375 * * * \\
(0.001)\end{array}$ & \\
\hline Export tariff & $\begin{array}{c}-0.050 * * * \\
(0.056)\end{array}$ & & $\begin{array}{c}-0.025^{* * *} \\
(0.003)\end{array}$ & \\
\hline Inverse Mills ratio & $\begin{array}{c}0.004 * * \\
(0.001)\end{array}$ & & $\begin{array}{c}0.006 * * * \\
(0.001)\end{array}$ & \\
\hline
\end{tabular}

Standard errors are bootstrapped and reported in parenthesis. $* * * \mathrm{p}<0.01, * * \mathrm{p}<0.05, * \mathrm{p}<0.1 ; \mathrm{p}$-values reported in brackets.

Year and industry effects, worker characteristics, and a constant were included in every equation. Another household member has a formal job indicator is included only in the selection equation. Sample weights used. 
Table 7 - Estimates of the effects of trade policy changes on the average informal wages.

\begin{tabular}{|c|c|c|c|c|}
\hline \multirow{3}{*}{ Independent Variables / Technique } & \multicolumn{4}{|c|}{ Informal wage } \\
\hline & (1) & (2) & (3) & (4) \\
\hline & 2SLS & OLS & 2SLS & OLS \\
\hline Import tariff & $\begin{array}{c}0.126 \\
(0.105)\end{array}$ & $\begin{array}{l}0.094^{*} \\
(0.051)\end{array}$ & $\begin{array}{l}0.373^{*} \\
(0.192)\end{array}$ & $\begin{array}{l}0.185^{*} \\
(0.096)\end{array}$ \\
\hline Export tariff & $\begin{array}{c}0.055 \\
(0.164)\end{array}$ & $\begin{array}{c}0.076 \\
(0.126)\end{array}$ & $\begin{array}{l}-0.136 \\
(0.261)\end{array}$ & $\begin{array}{l}-0.003 \\
(0.236)\end{array}$ \\
\hline Inverse mills ratio & $\begin{array}{c}-0.199 * * * \\
(0.019) \\
\end{array}$ & $\begin{array}{c}-0.200 * * * \\
(0.018) \\
\end{array}$ & $\begin{array}{c}-0.226 * * * \\
(0.049) \\
\end{array}$ & $\begin{array}{c}-0.234 * * * * \\
(0.049) \\
\end{array}$ \\
\hline State*year effects & No & No & Yes & Yes \\
\hline Observations & 135148 & 135148 & 135148 & 135148 \\
\hline Endogeneity Test & $\begin{array}{c}0.122 \\
{[0.727]}\end{array}$ & & $\begin{array}{c}1.443 \\
{[0.230]}\end{array}$ & \\
\hline Test of both Import tariff $=0$ and Export tariff $=0$ & $\begin{array}{c}4.96^{*} \\
{[0.084]}\end{array}$ & $\begin{array}{l}6.72 * * \\
{[0.035]}\end{array}$ & $\begin{array}{c}3.85 \\
{[0.146]}\end{array}$ & $\begin{array}{c}1.95 \\
{[0.145]}\end{array}$ \\
\hline Instruments (estimated coefficient in $1^{\text {st }}$ stage) & & & & \\
\hline Colombian tariff & $\begin{array}{c}0.417 * * * \\
(0.003)\end{array}$ & & $\begin{array}{c}0.417 * * * \\
(0.104)\end{array}$ & \\
\hline Export tariff & $\begin{array}{c}0.037 * * * \\
(0.007)\end{array}$ & & $\begin{array}{c}0.054 \\
(0.156)\end{array}$ & \\
\hline Inverse Mills ratio & $\begin{array}{c}-0.015 * * * \\
(0.002)\end{array}$ & & $\begin{array}{c}-0.028 * * * \\
(0.007)\end{array}$ & \\
\hline
\end{tabular}

Standard errors are bootstrapped and reported in parenthesis. $* * * \mathrm{p}<0.01, * * \mathrm{p}<0.05, * \mathrm{p}<0.1 ; \mathrm{p}$-values reported in brackets.

Year and industry effects, worker characteristics, and a constant were included in every equation. Another household member has a formal job indicator is included only in the selection equation. Sample weights used. 
Table 8 - Estimates of the effects of trade policy changes on the average formal wages using non-linear identification.

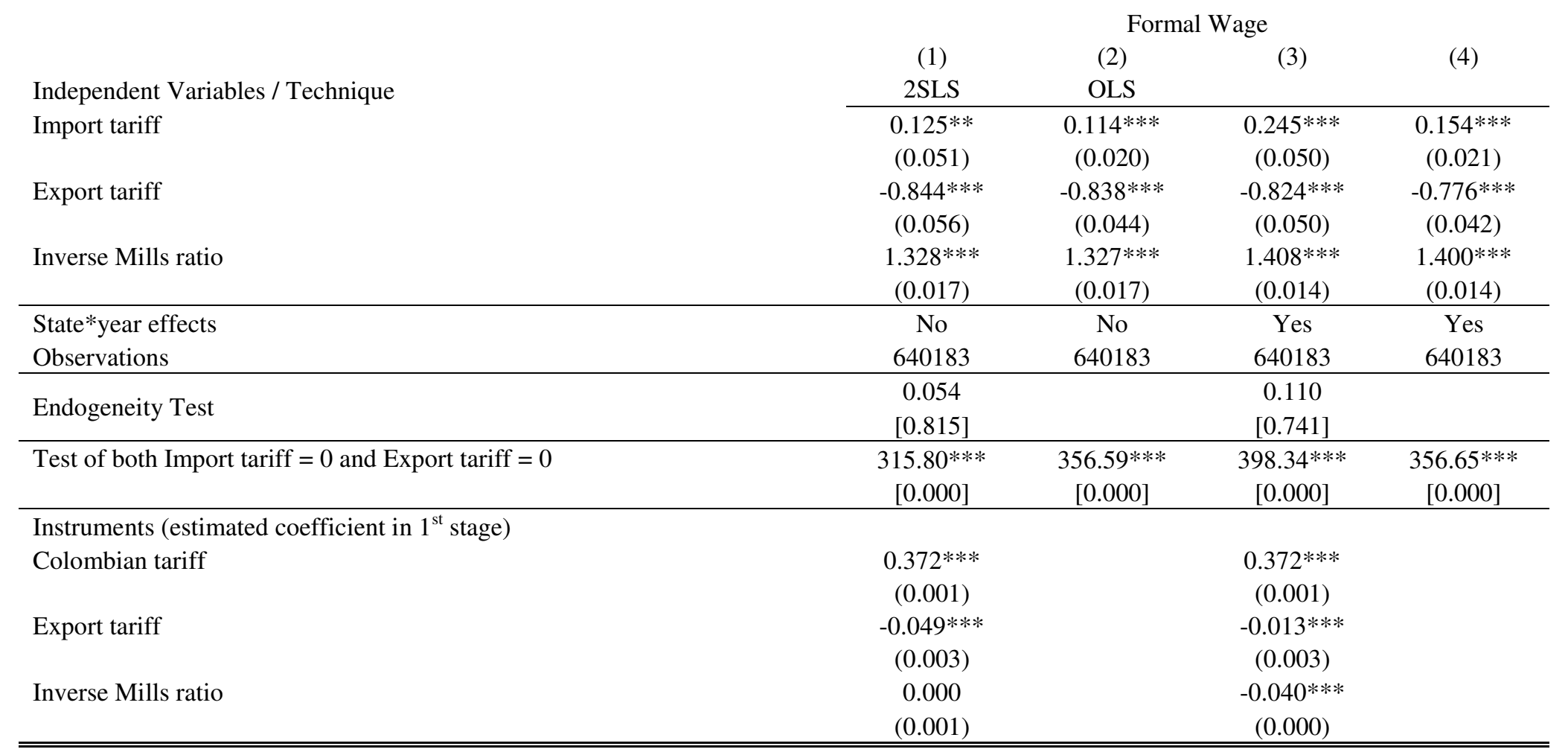

Standard errors are bootstrapped and reported in parenthesis. *** $\mathrm{p}<0.01, * * \mathrm{p}<0.05, * \mathrm{p}<0.1 ; \mathrm{p}$-values reported in brackets.

Both selection and regime equations include year and industry effects, worker characteristics, and a constant. Sample weights used. 
Table 9 - Estimates of the effects of trade policy changes on the average informal wages using non-linear identification.

\begin{tabular}{|c|c|c|c|c|}
\hline \multirow[b]{3}{*}{ Independent Variables / Technique } & \multicolumn{4}{|c|}{ Informal wage } \\
\hline & (1) & (2) & (3) & (4) \\
\hline & 2 SLS & OLS & 2SLS & OLS \\
\hline Import tariff & $\begin{array}{l}-0.035 \\
(0.108)\end{array}$ & $\begin{array}{l}-0.088^{*} \\
(0.052)\end{array}$ & $\begin{array}{c}0.150 \\
(0.112)\end{array}$ & $\begin{array}{l}-0.085 \\
(0.057)\end{array}$ \\
\hline Export tariff & $\begin{array}{c}1.357 * * * \\
(0.204)\end{array}$ & $\begin{array}{c}1.410 * * * \\
(0.149)\end{array}$ & $\begin{array}{c}0.776 * * * \\
(0.216)\end{array}$ & $\begin{array}{c}1.023 * * * \\
(0.151)\end{array}$ \\
\hline Inverse Mills ratio & $\begin{array}{c}-1.224 * * * \\
(0.068) \\
\end{array}$ & $\begin{array}{c}-1.239^{* * * *} \\
(0.062) \\
\end{array}$ & $\begin{array}{c}-1.006^{* * *} \\
(0.062) \\
\end{array}$ & $\begin{array}{c}-1.098 * * * \\
(0.053) \\
\end{array}$ \\
\hline $\begin{array}{l}\text { State*year effects } \\
\text { Observations }\end{array}$ & $\begin{array}{c}\text { No } \\
135148\end{array}$ & $\begin{array}{c}\text { No } \\
135148\end{array}$ & $\begin{array}{c}\text { Yes } \\
135148\end{array}$ & $\begin{array}{c}\text { Yes } \\
135148\end{array}$ \\
\hline Endogeneity Test & $\begin{array}{c}0.314 \\
{[0.575]}\end{array}$ & & $\begin{array}{c}1.684 \\
{[0.194]}\end{array}$ & \\
\hline Test of both Import tariff $=0$ and Export tariff $=0$ & $\begin{array}{c}107.94 * * * \\
{[0.000]}\end{array}$ & $\begin{array}{c}105.19^{* * * *} \\
{[0.000]} \\
\end{array}$ & $\begin{array}{c}69.64 * * * \\
{[0.000]} \\
\end{array}$ & $\begin{array}{c}53.64 * * * \\
{[0.000]} \\
\end{array}$ \\
\hline Instruments (estimated coefficient in $1^{\text {st }}$ stage) & & & & \\
\hline Colombian tariff & $\begin{array}{c}0.405^{* * * *} \\
(0.003)\end{array}$ & & $\begin{array}{c}0.389^{* * * *} \\
(0.003)\end{array}$ & \\
\hline Export tariff & $\begin{array}{c}0.272 * * * \\
(0.008)\end{array}$ & & $\begin{array}{c}0.338 * * * \\
(0.008)\end{array}$ & \\
\hline Inverse Mills ratio & $\begin{array}{c}-0.201 * * * \\
(0.003) \\
\end{array}$ & & $\begin{array}{c}-0.271 * * * * \\
(0.004) \\
\end{array}$ & \\
\hline
\end{tabular}

Standard errors are bootstrapped and reported in parenthesis. *** $\mathrm{p}<0.01, * * \mathrm{p}<0.05, * \mathrm{p}<0.1 ; \mathrm{p}$-values reported in brackets.

Both selection and regime equations include year and industry effects, worker characteristics, and a constant. Sample weights used. 
Table 10 - Estimates of the effects of trade policy changes on the probability of a worker having an informal job, using an alternative definition of informality, and when export tariff is omitted.

\begin{tabular}{|c|c|c|c|c|c|c|}
\hline \multirow{2}{*}{$\begin{array}{l}\text { Dependent Variable: } \\
\text { Independent Variables / Technique }\end{array}$} & \multicolumn{2}{|c|}{$\begin{array}{c}\text { Signed labor contract } \\
\text { indicator }\end{array}$} & \multicolumn{4}{|c|}{ informal job indicator } \\
\hline & $\begin{array}{c}(1) \\
2 S L S\end{array}$ & $\begin{array}{c}(2) \\
\text { IVProbit }\end{array}$ & $\begin{array}{l}(3) \\
\text { OLS }\end{array}$ & $\begin{array}{c}(4) \\
\text { Probit }\end{array}$ & $\begin{array}{c}(5) \\
\text { 2SLS }\end{array}$ & $\begin{array}{c}6) \\
\text { IVProbit }\end{array}$ \\
\hline Import tariff & $\begin{array}{l}-0.060 \\
(0.053)\end{array}$ & $\begin{array}{c}0.013 \\
(0.280)\end{array}$ & $\begin{array}{c}0.024 \\
(0.034)\end{array}$ & $\begin{array}{c}0.159 \\
(0.144)\end{array}$ & $\begin{array}{l}-0.034 \\
(0.049)\end{array}$ & $\begin{array}{c}0.369 \\
(0.310)\end{array}$ \\
\hline Export tariff & $\begin{array}{l}0.159^{*} \\
(0.087)\end{array}$ & $\begin{array}{c}1.434 * * * \\
(0.446)\end{array}$ & & & & \\
\hline Observations & 775331 & 775331 & 775331 & 775331 & 775331 & 775331 \\
\hline Under identification test (Kleibergen-Paap rk LM statistic) & $\begin{array}{l}3.153^{*} \\
{[0.076]}\end{array}$ & & & & $\begin{array}{l}3.589^{*} \\
{[0.058]}\end{array}$ & \\
\hline Weak identification test Kleibergen-Paap rk Wald F statistic & 16.16 & & & & 18.42 & \\
\hline Stock-Yogo $10 \%$ max IV relative bias critical values & 16.38 & & & & 16.38 & \\
\hline Endogeneity Test & $\begin{array}{l}1.2425 \\
{[0.265]}\end{array}$ & & & & $\begin{array}{c}1.668 \\
{[0.197]}\end{array}$ & \\
\hline Wald Exogeneity test & & $\begin{array}{c}0.26 \\
{[0.607]}\end{array}$ & & & & $\begin{array}{c}0.667 \\
{[0.414]}\end{array}$ \\
\hline Test of both Import tariff $=0$ and Export tariff $=0$ & $\begin{array}{c}3.73 \\
{[0.155]}\end{array}$ & $\begin{array}{c}13.21 * * * \\
{[0.001]}\end{array}$ & & & & \\
\hline Estimated coefficients in the $1^{\text {st }}$ stage & & & & & & \\
\hline Colombian tariff (excluded instrument) & $\begin{array}{c}0.378 * * * \\
{[0.094]}\end{array}$ & $\begin{array}{c}0.377 * * * \\
{[0.094]}\end{array}$ & & & $\begin{array}{c}0.372 * * * \\
(0.086)\end{array}$ & $\begin{array}{c}0.372 * * * \\
(0.086)\end{array}$ \\
\hline Export tariff (included instrument) & $\begin{array}{l}-0.044 \\
(0.167)\end{array}$ & $\begin{array}{l}-0.044 \\
(0.168)\end{array}$ & & & & \\
\hline
\end{tabular}


Table 11 - Estimates of the effects of trade policy changes on the average formal and informal wages, with export tariff variable excluded.

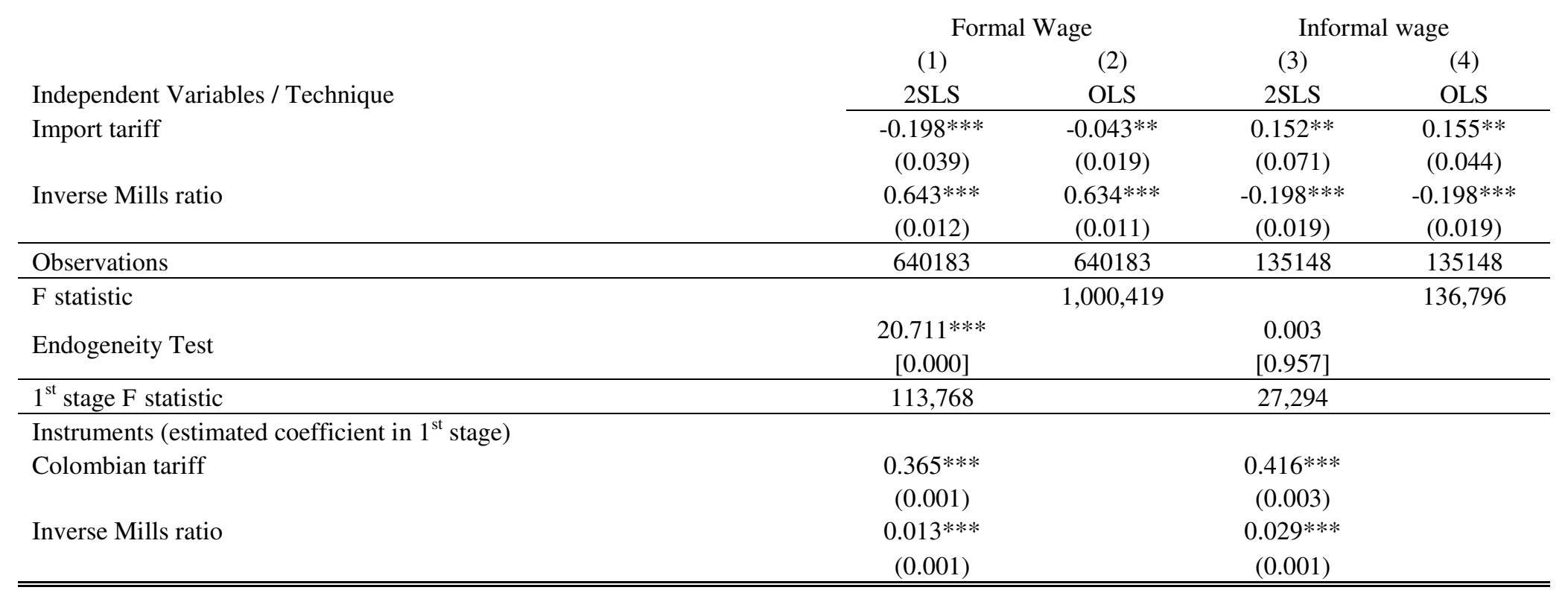

Standard errors are bootstrapped and reported in parenthesis. *** $\mathrm{p}<0.01, * * \mathrm{p}<0.05, * \mathrm{p}<0.1 ; \mathrm{p}$-values reported in brackets.

Year and industry effects, worker characteristics, and a constant were included in every stage of all estimated models. Another household member has a formal job indicator is included only in the selection equation. Sample weights used. 
Table 12 - Placebo estimates of the effects of trade policy changes on the probability of a worker having an informal job using 1981-1993 data.

Dependent Variable: informal job indicator

\begin{tabular}{|c|c|c|c|c|}
\hline Independent Variables / Technique & $\begin{array}{l}\text { (1) } \\
\text { OLS }\end{array}$ & $\begin{array}{c}(2) \\
\text { Probit }\end{array}$ & $\begin{array}{c}(3) \\
2 S L S\end{array}$ & $\begin{array}{c}(4) \\
\text { IVProbit }\end{array}$ \\
\hline \multirow[t]{2}{*}{ Import tariff } & 0.005 & -0.189 & 0.008 & 0.447 \\
\hline & $(0.025)$ & $(0.142)$ & $(0.069)$ & $(0.478)$ \\
\hline \multirow[t]{2}{*}{ Export tariff } & -0.025 & $0.621 * *$ & -0.026 & 0.351 \\
\hline & $(0.049)$ & $(0.296)$ & $(0.049)$ & $(0.381)$ \\
\hline Observations & 520737 & 520737 & 520737 & 520737 \\
\hline \multirow[t]{2}{*}{ Under identification test (Kleibergen-Paap rk LM statistic) } & & & $2.95^{*}$ & \\
\hline & & & [0.086] & \\
\hline Weak identification test Kleibergen-Paap rk Wald F statistic & & & 9.19 & \\
\hline Stock-Yogo test critical value for $10 \% \max$ IV size & & & 16.38 & \\
\hline \multirow{2}{*}{ Endogeneity Test } & & & 0.001 & \\
\hline & & & {$[0.097]$} & \\
\hline \multirow{2}{*}{ Wald Exogeneity test } & & & & 2.296 \\
\hline & & & & [0.130] \\
\hline \multirow[t]{2}{*}{ Test of both Import tariff $=0$ and Export tariff $=0$} & 0.13 & $4.78^{*}$ & 0.29 & 3.99 \\
\hline & [0.879] & {$[0.091]$} & [0.865] & [0.136] \\
\hline $1^{\text {st }}$ stage F statistic & & & 23,772 & 23,772 \\
\hline \multicolumn{5}{|l|}{ Estimated coefficients in the $1^{\text {st }}$ stage } \\
\hline \multirow[t]{2}{*}{ Colombian tariff (excluded instrument) } & & & $0.302 * * *$ & $0.302 * * *$ \\
\hline & & & $(0.100)$ & $(0.100)$ \\
\hline \multirow[t]{2}{*}{ Export tariff (included instrument) } & & & -0.012 & -0.012 \\
\hline & & & $(0.171)$ & $(0.171)$ \\
\hline
\end{tabular}

Standard errors are clustered on industry by year reported in parentheses. $* * * \mathrm{p}<0.01, * * \mathrm{p}<0.05, * \mathrm{p}<0.1 ; \mathrm{p}$-values reported in brackets.

Year and industry effects, worker characteristics, another household member has a formal job indicator, and a constant were included in every stage of all estimated models. Sample weights used. 
Figure 1 - Informality share in services and manufacturing in Brazil, 1984-2001.

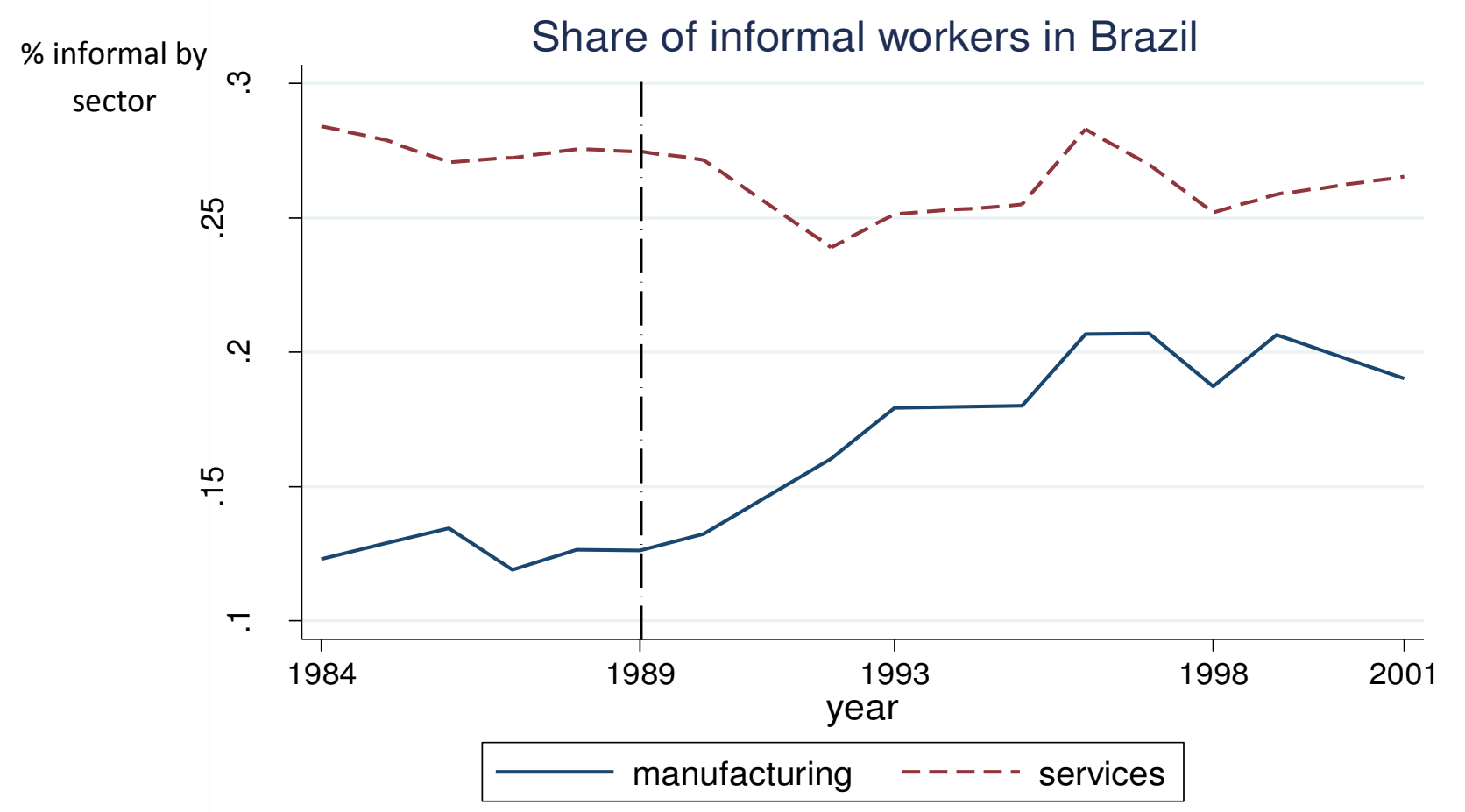

Source: PNAD data.

Note: Dashed vertical line indicates the start of Brazil's trade liberalization 
Figure 2 - Wage $\left(\mathrm{W}_{\mathrm{i}}\right)$ and expected cost of a worker $\left(\mathrm{b}_{\mathrm{i}}\right)$ under formal and informal labor contracts for firms that serve the Home market, the Foreign market, or both.

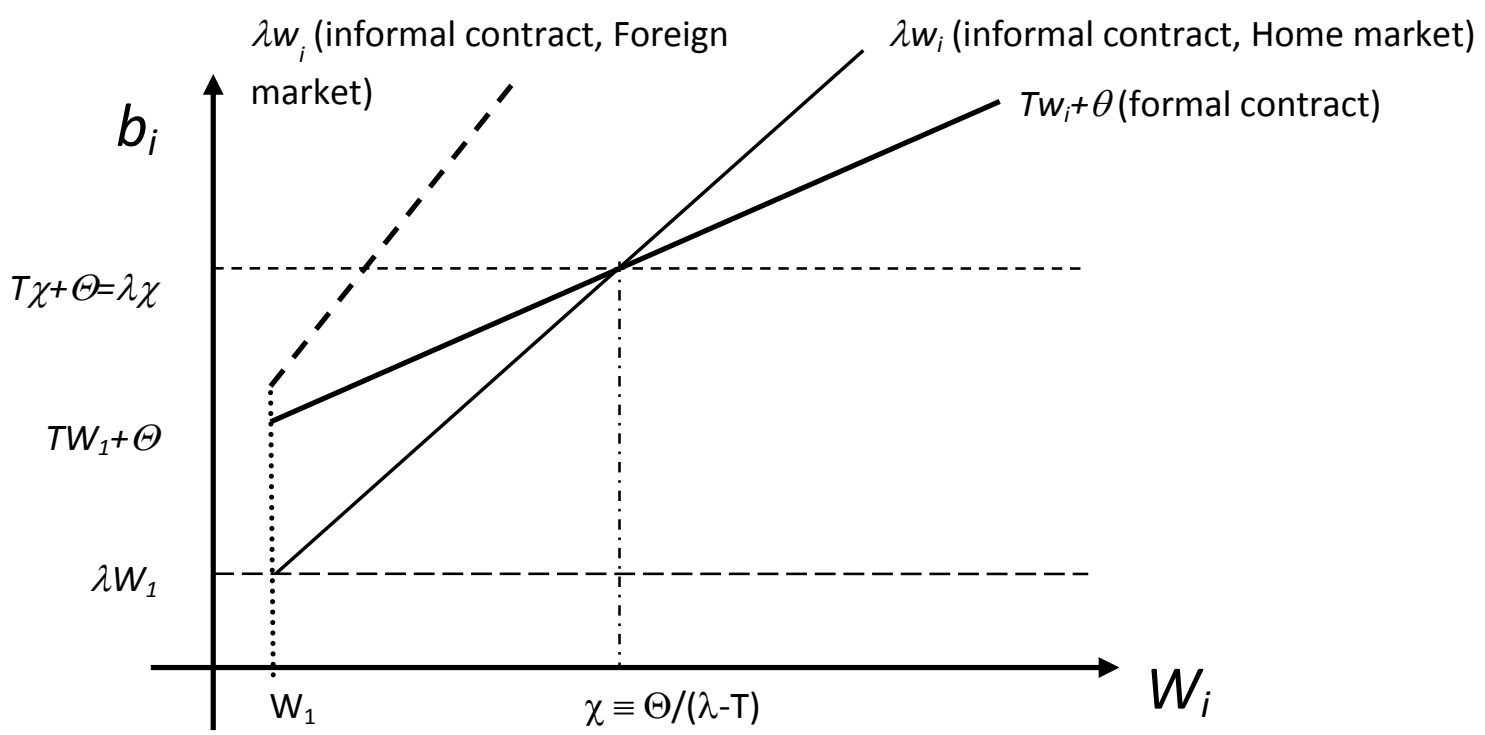


Figure 3 - Firms' entry cutoffs, choice of labor contracts, and markets served in an open economy.

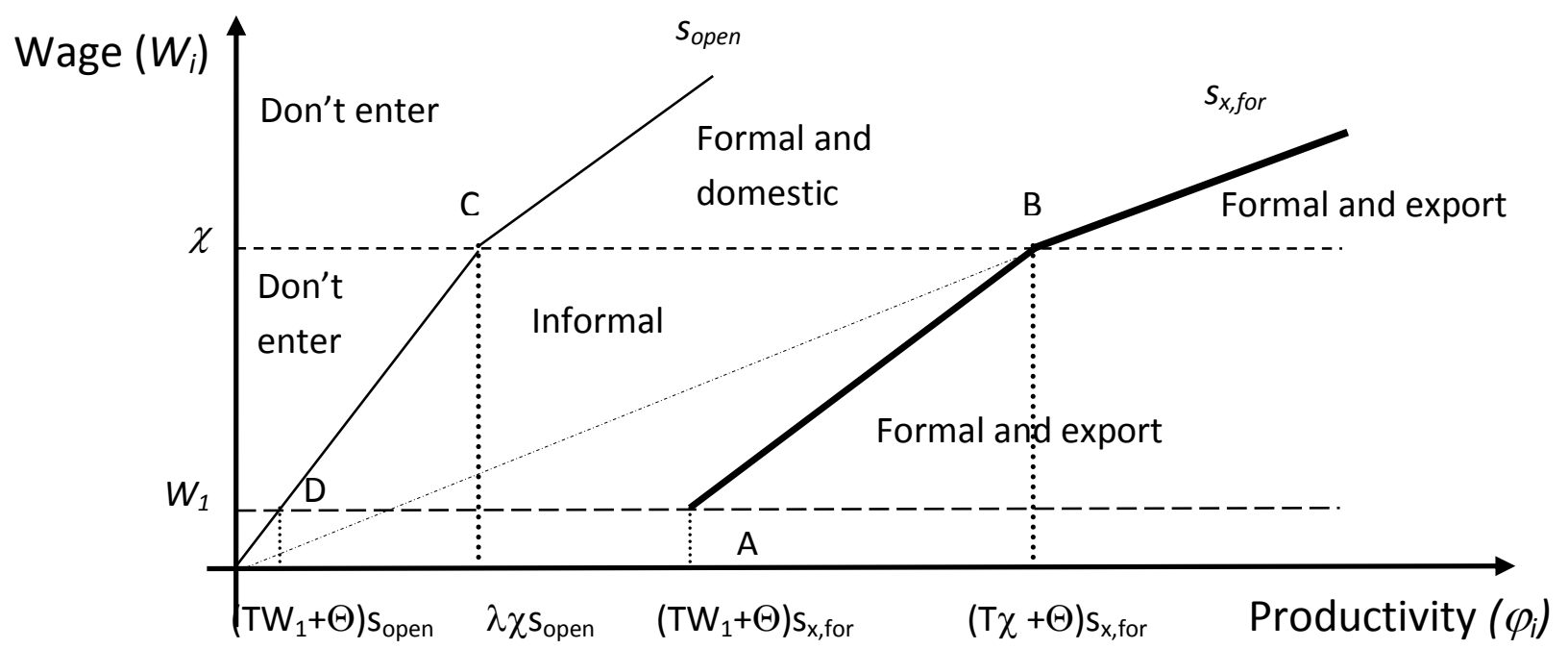


Figure 4 - Brazilian import tariff by industry for the 1989-2001 period.

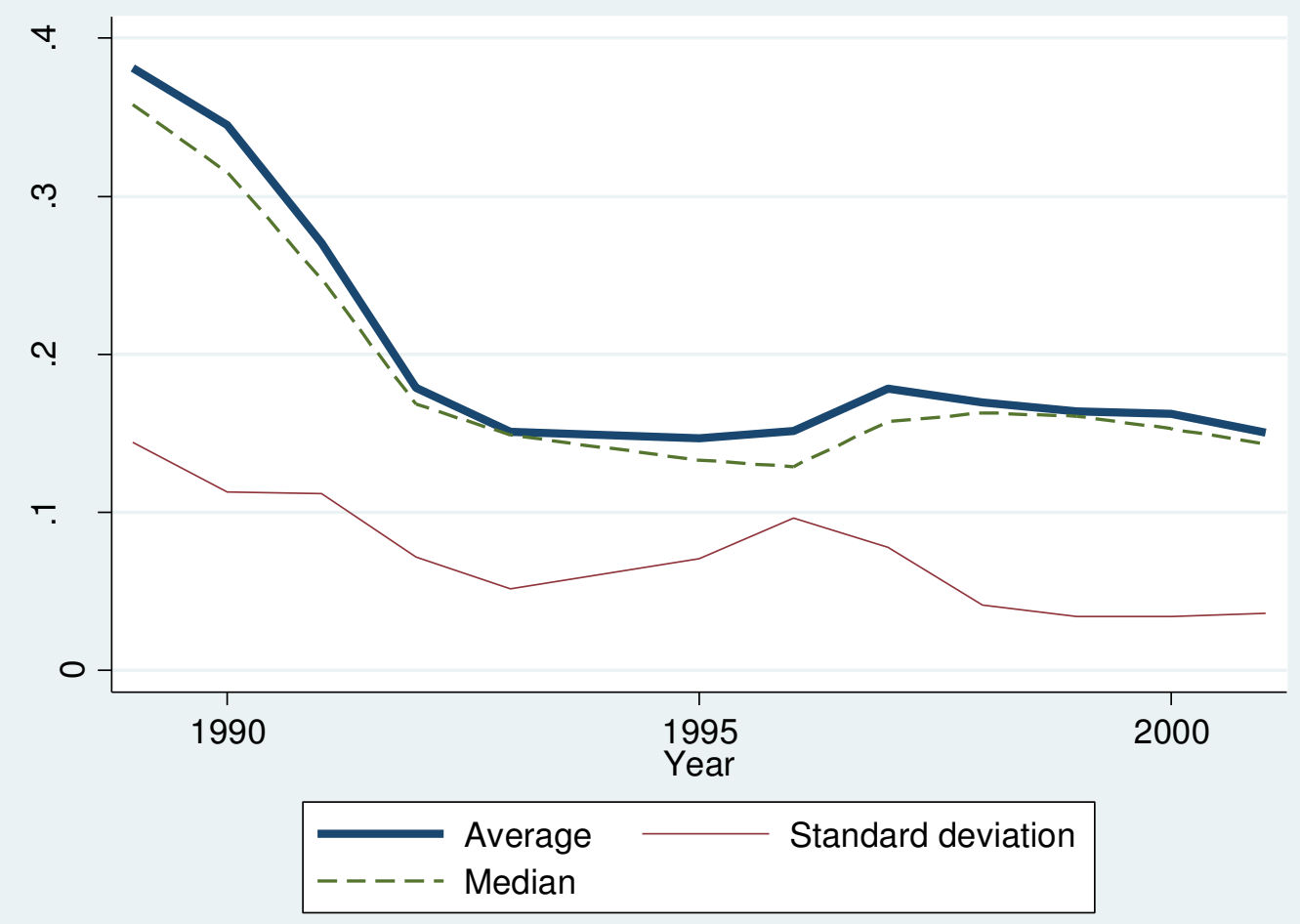


Figure 5 - Export tariffs on Brazilian-made goods by industry for the 1989-2001 period.

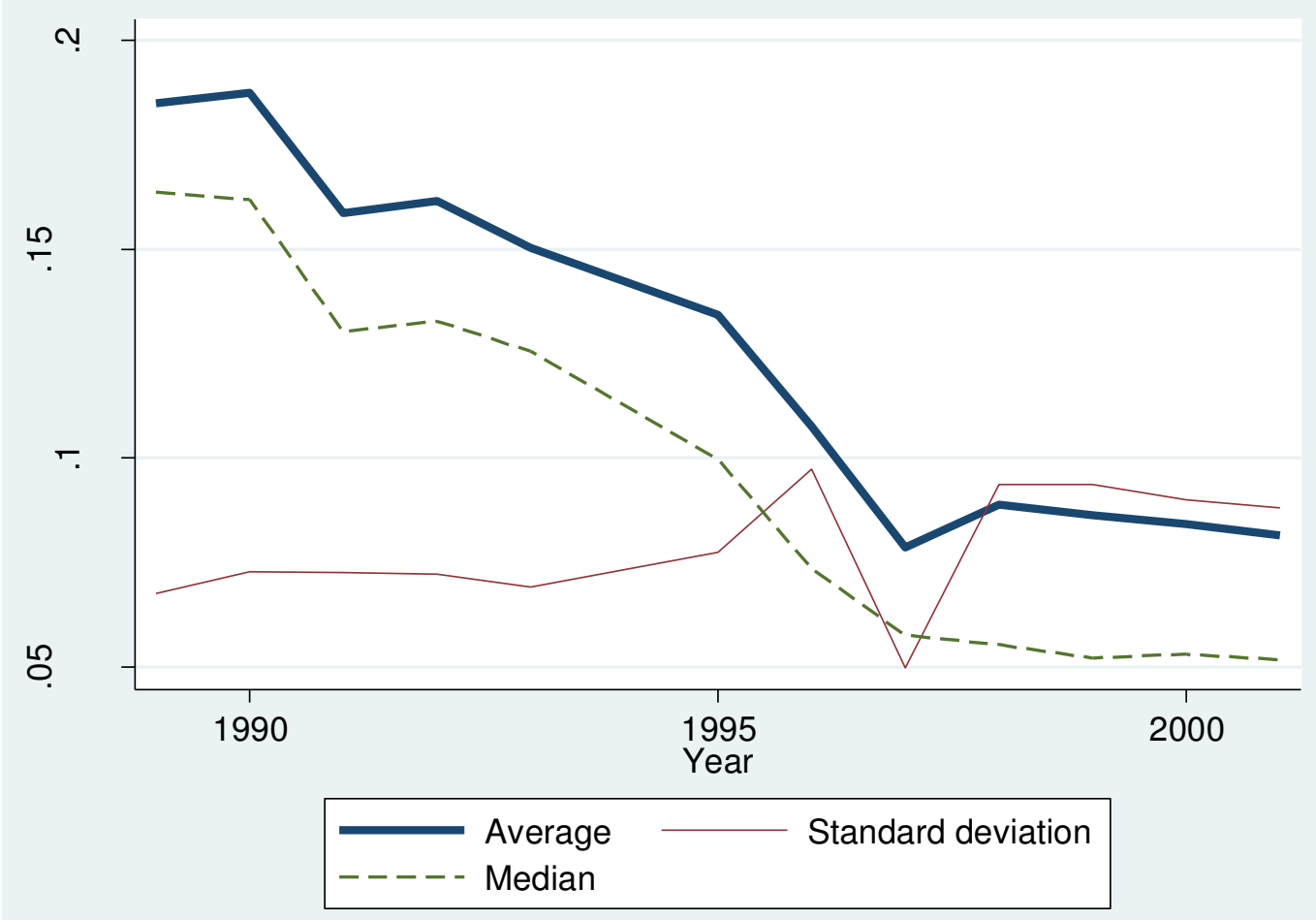




\section{Online Appendix}

\section{A.1 Efficiency Wage Problem with Government Transfers}

The flow value of a non-shirker worker employed at firm $i$ is given by equation (19). Following Davis and Harrigan (2011), I also have to assume the parameter restriction $m_{i} \delta>e-1$, to ensure the existence of a solution to the problem. This condition is satisfied as long as the likelihood of exogenous job loss and the utility penalty of effort are small.

$$
r V_{E_{i}}^{N}=\frac{w_{i}}{e}+\frac{t r}{P}+\delta\left(V_{U}-V_{E_{i}}^{N}\right) ; w_{i} \equiv \frac{W_{i}}{P}
$$

Similarly, the flow value of a shirker worker employed at firm $i$ is

$$
r V_{E_{i}}^{S}=w_{i}+\frac{t r}{P}+\left(\delta+m_{i}\right)\left(V_{U}-V_{E_{i}}^{S}\right)
$$

Let's impose the non-shirking condition, $V_{E_{i}}^{N}=V_{E_{i}}^{S}=V_{E_{i}}$

$$
\frac{1}{r+\delta}\left[\frac{w_{i}}{e}+\frac{t r}{P}+\delta V_{U}\right]=\frac{1}{r+\delta+m_{i}}\left[w_{i}+\frac{t r}{P}+\left(\delta+m_{i}\right) V_{U}\right]
$$

Next, I solve for $r V_{U}$.

$$
r V_{U}=\frac{w_{i}}{m_{i}}\left[\frac{(1-e)(r+\delta)+m_{i}}{e}\right]+\frac{t r}{P}
$$

Isolating $w_{i}$ in the previous equation leads to equation (20).

$$
w_{i}=\frac{r V_{U}}{\widehat{m}_{i}}-\frac{t r}{\widehat{m}_{i} P} ; \widehat{m}_{i} \equiv \frac{m_{i}-(e-1)(r+\delta)}{e m_{i}}
$$

Now, let's calculate $V_{E_{i}}-V_{U}$,

$$
\left(r+\delta+m_{i}\right)\left[V_{E_{i}}-V_{U}\right]=-r V_{U}+\frac{W_{i}}{P}+\frac{t r}{P} .
$$

Plugging $r V_{U}$ into the above equation, I obtain

$$
V_{E_{i}}-V_{U}=\frac{W_{i}}{m_{i} P}\left[\frac{e-1}{e}\right] .
$$


For any two firms $i$ and $j$ with different $i \neq j$, I use equation (20) to construct the following wage ratios,

$$
\frac{w_{i}}{w_{j}}=\frac{\widehat{m}_{j}}{\widehat{m}_{i}}=\frac{W_{i}}{W_{j}}
$$

Let $W_{1}$ be the wage paid by the firm with monitoring ability $\bar{m}$, then

$$
W_{i}=W_{1} \frac{\widehat{\bar{m}}}{\widehat{m_{i}}}>W_{1} ; \frac{\partial W_{i}}{\partial m_{i}}=-\frac{(e-1)(r+\delta)}{\bar{m}\left[m_{i}-(e-1)(r+\delta)\right]}<0 .
$$

Now, it is time to aggregate the firm-level variables in order to solve for the unemployment level. Given that the wage density is common knowledge, we can calculate:

$$
V_{E}=E\left[V_{E_{i}}\right]=\left[\frac{e-1}{e P}\right] E\left(\frac{W_{i}}{m_{i}}\right)+V_{U}
$$

The flow value of being unemployed is given by

$$
r V_{U}=b\left(V_{E}-V_{U}\right)+\frac{t r}{P}=b\left[\frac{e-1}{e P}\right] E\left(\frac{W_{i}}{m_{i}}\right)+\frac{t r}{P}
$$

In equilibrium, unemployment inflow equals unemployment outflow, $b U=\delta(L-U)$, where $b$ is the unemployment escape rate. Let $u \equiv U / L$, then

$$
r V_{U}=\delta\left(\frac{1-u}{u}\right)\left[\frac{e-1}{e P}\right] E\left(\frac{W_{i}}{m_{i}}\right)+\frac{t r}{P}
$$

Plugging $r V_{U}$ into the wage equation, we obtain for firm $i$,

$$
W_{i}=\frac{\delta}{\widehat{m}_{i}}\left(\frac{1-u}{u}\right)\left[\frac{e-1}{e P}\right] E\left(\frac{W_{i}}{m_{i}}\right)
$$

Then for the firm with monitoring ability $\bar{m}$, we have

$$
u=\left[\frac{B_{1} E\left(\frac{W_{i}}{m_{i}}\right)}{W_{1}+B_{1} E\left(\frac{W_{i}}{m_{i}}\right)}\right], B_{1} \equiv\left[\frac{\bar{m} \delta(e-1)}{\bar{m}-\delta(e-1)}\right] .
$$

Notice that as in Melitz (2003) and Davis and Harrigan (2011), I also let $r$ go to zero. 


\section{A.2 Proofs of Lemmas and Propositions}

Proposition 1. The general equilibrium is characterized by the solution of the system of equations comprised by equations (5)-(10) and the entry and export cutoff equations. This solution is unique.

Proof. The model's endogenous variables are $s_{\text {open }}, s_{x, f o r}, s_{x, f o r}^{*}, W_{1}, M, P, Q, E\left(W_{i} / m_{i}\right), u$, and $t r$. The general equilibrium is described by the following equations. I define $\widetilde{s}(s)$ as a measure of aggregate inverse marginal costs for firms with $s_{i} \geq s$,

$$
\widetilde{s}(\hat{s}) \equiv \frac{1}{1-G(\hat{s})}\left[\int_{\hat{s}}^{\infty} s^{\sigma-1} G(s) d s\right]^{\frac{1}{\sigma-1}}
$$

The free entry condition (FE) states that a sufficient mass of ex ante identical firms enters the market so that the expected profit from entry equals the fixed cost of entry, and it is depicted in equation (5), where $J(\widetilde{s}) \equiv\left[\left(\int_{\widetilde{s}}^{\infty} \frac{s^{\sigma-1}}{\widetilde{s}} G(s) d s\right)^{\sigma-1}-1\right]$

$$
J\left(s_{\text {open }}\right) W_{1} f+J\left(s_{x, f o r}\right) W_{1} f_{x}=\delta f_{e} W_{1}
$$

The zero profit cutoff condition requires the marginal entrant to have zero profits, i.e., the variable profit $\left(\pi^{v}\right)$ must be equal to the per-period fixed cost of production, as depicted in equation $(22)$.

$$
\pi_{d}^{v}\left(s_{\text {open }}\right)=\sigma^{-1}\left(\rho P s_{\text {open }}\right)^{\sigma-1} Q=W_{1} f
$$

Similarly, the zero cutoff profit condition for exporting states that for the marginal entrant in the Foreign market, the variable profit from exporting must equal the fixed cost of exporting as shown in equation (23).

$$
\pi_{x}^{v}\left(s_{x, f o r}\right)=\sigma^{-1}\left(\rho s_{x, f o r}\right)^{\sigma-1} A=W_{1} f_{x}
$$

And, the Foreign exporter zero profit cutoff for entering the Home market must equal the fixed cost of exporting, as shown in equation (24). 


$$
\pi_{x}^{*, v}\left(s_{x, f o r}^{*}\right)=\sigma^{-1}\left(\rho P s_{x, f o r}^{*} / \tau\right)^{\sigma-1} Q=W_{1}^{*} f_{x}
$$

The remaining equations needed are (6)-(10). Notice that by means of recursive substitution, the general equilibrium ends up depending only on $W_{1}$ and $s_{x, f o r}$. This is because all of the other endogenous variables can be written as a function of these two variables. As a result, the general equilibrium problem can be defined by equation (23) and equation (25), which is a modified version of equation (11) as demonstrated below.

$$
\frac{A M\left(W_{1}, s_{x, f o r}\right)}{1-G\left(s_{x, f o r}\right)} \int_{s_{x, f o r}}^{\infty}\left(\frac{\rho s}{\tau^{*}}\right)^{\sigma-1} d G(s)=\frac{Q\left(W_{1}, s_{x, f o r}\right) M^{*}}{1-G^{*}\left[s_{x, f o r}^{*}\left(W_{1}, s_{x, f o r}\right)\right]} \int_{s_{x, f \text { or }}^{*}}^{\infty}\left(\frac{\rho s P\left(W_{1}, s_{x, f o r}\right)}{\tau}\right)^{\sigma-1} d G^{*}(s)
$$

This is the same approach used by Demidova and Rodriguez-Clare (2011), and it works here because my model is isomorphic to theirs. Therefore, the proof of equilibrium existence is similar and is omitted here.

Lemma 1. A decrease in Home tariffs leads to an increase in $s_{\text {open }}$ and a reduction in $W_{1}$ and $s_{x, f o r}$. On the other hand, a decrease in Foreign tariffs leads to a reduction in $s_{x, \text { for }}$ and an increase in $s_{\text {open }}$ and $W_{1}$.

Proof. A reduction in Home import tariffs $(\tau)$ affects only equation (25), i.e., the trade balance condition. It follows that for a fixed export cutoff $\left(s_{x, f o r}\right)$, a reduction in Home import tariffs will increase imports and force a reduction in Home wages, $d W_{1} / d \tau>0$, which boosts exports. ${ }^{32}$ So, the trade flows remain balanced. Through equation (23), the reduction in $W_{1}$ leads to a decrease in $s_{x, f o r}\left(\partial s_{x, f o r} / \partial \tau>0\right)$. The free entry condition, equation (5), implies that $s_{\text {open }}$ moves in the opposite direction from $s_{x, \text { for }}$, so a decrease in $\tau$ leads to an increase in $s_{\text {open }}\left(\partial s_{\text {open }} / \partial \tau<0\right)$.

A reduction in Foreign import tariffs $\left(\tau^{*}\right)$ affects equation (23), and for a fixed export cutoff it implies that $W_{1}$ has to increase, that is $d W_{1} / d \tau^{*}<0$. The increase in $W_{1}$ leads to a decrease in $s_{x, \text { for }}\left(\partial s_{x, \text { for }} / \partial \tau^{*}>0\right)$ through equation $(25)$, which means the marginal cost export cutoff increases. Equation (5) implies that $s_{\text {open }}$ moves in the opposite direction from $s_{x, \text { for }}$, so a decrease

\footnotetext{
${ }^{32}$ The fact that $W_{1}$ is increasing in $\tau$ and decreasing in $\tau^{*}$ is formally proved in Demidova and Rodriguez-Clare (2011) Lemma 1.
} 
in $\tau$ leads to an increase in $s_{\text {open }}\left(\partial s_{\text {open }} / \partial \tau^{*}<0\right)$.

Proposition 2. The effect of a reduction in the Home import tariff on the share of informal workers in total industry employment is ambiguous.

a. If condition (S1) holds, i.e., $0>\frac{\partial \Psi}{\partial \varphi} \Psi^{-1}>\frac{1-\sigma}{\varphi}$, then the share of informal workers will decrease with a reduction in $\tau$.

b. If conditions (S2) and (S3) hold, which are $\frac{1-\sigma}{\varphi}>\frac{f}{f_{x}}\left[1+\left(\frac{\sigma f_{x} \tau^{*}}{A \rho}\right)^{\frac{1}{\sigma-1}}\right] \frac{\partial \Psi}{\partial \varphi} \Psi^{-1}$ and $\operatorname{Pr}[W \geq \chi]>$ $\tau^{\sigma}\left(\frac{f}{f_{x}}\right)^{\frac{\sigma}{\sigma-1}} \operatorname{Pr}[W<\chi]$, respectively, then the share of informal workers will increase with a reduction in $\tau$.

Proof. Notice that $\frac{\partial \text { share }}{\partial s_{x, f o r}}=\left(L^{v, \text { inf }}+L^{v, f o r}\right)^{2}\left\{\frac{\partial L^{v, \text { inf }}}{\partial s_{x, f o r}} L^{v, f o r}-\frac{\partial L^{v, f o r}}{\partial s_{x, f o r}} L^{v, \text { inf }}\right\}$. The first term inside the curly brackets is positive since $\partial L^{v, \text { inf }} / \partial s_{x, \text { for }}>0$. The second term is also positive because $\partial L^{v, \text { for }} / \partial s_{x, \text { for }}>0$. So, $\frac{\partial \text { share }}{\partial s_{x, f o r}}>0$. Hence, $\frac{\partial \text { share }}{\partial s_{x, \text { for }}} \frac{\partial s_{x, \text { for }}}{\partial \tau}>0$.

Now, let's examine in detail the sign of $\frac{\partial \text { share }}{\partial s_{\text {open }}}=\left(L^{v, \text { inf }}+L^{v, \text { for }}\right)^{2}\left\{\frac{\partial L^{v, \text { inf }}}{\partial s_{\text {open }}} L^{v, \text { for }}-\frac{\partial L^{v, \text { for }}}{\partial s_{\text {open }}} L^{v, \text { inf }}\right\}$. The first term inside the curly brackets is positive, while $\partial L^{v, f o r} / \partial s_{\text {open }}>0$. So the resulting sign of $\partial$ share/ $\partial s_{\text {open }}$ is ambiguous.

a. The strategy adopted here to find sufficient conditions for a sign is to find a term that can dominate $L^{v, \text { for }} \partial L^{v, \text { inf }} / \partial s_{\text {open }}$. Thus, the sign ambiguity can be solved if $\left|\frac{\partial s_{x, \text { for }}}{\partial \tau} \frac{\partial L^{v, f o r}}{\partial s_{x, \text { for }}} L^{v, \text { inf }}\right|>$ $\left|\frac{\partial s_{\text {open }}}{\partial \tau} \frac{\partial L^{v, f o r}}{\partial s_{\text {open }}} L^{v, \text { inf }}\right|$, which means that the number of formal jobs along the $s_{x, \text { for }}$ line for $W_{i}>\chi$ is larger than the number of formal jobs along the $s_{\text {open }}$ line. Such inequality holds if $\left|\partial s_{x, f o r} / \partial \tau\right|>$ $\left|\partial s_{\text {open }} / \partial \tau\right|$ and $\left|\partial L^{v, \text { for }} / \partial s_{x, \text { for }}\right|>\left|\partial L^{v, f o r} / \partial s_{\text {open }}\right|$. Lemma 2 guarantees that that the former inequality holds. The latter inequality is met if condition (S1) holds. The intuition is the following. For a given wage, as productivity increases, the firm-level employment increases at the $(\sigma-1) \varphi^{-1}$ rate. So, as long as the partial derivative of $\Psi$ with respect to productivity decreases at a slower rate, i.e., $0>\Psi(\varphi, W)^{-1} \frac{\partial \Psi(\varphi, W)}{\partial \varphi}>(1-\sigma) / \varphi$, there will be more formal workers employed in firms lying on $s_{x, f o r}$ than on $s_{\text {open }}$.

b. Sufficient conditions (S2) and (S3) are needed to ensure that $\left|\frac{\partial s_{\text {open }}}{\partial \tau} \frac{\partial L^{v, f o r}}{\partial s_{\text {open }}} L^{v, \text { inf }}\right|>$ $\left|\frac{\partial s_{\text {open }}}{\partial \tau} \frac{\partial L^{v, \text { inf }}}{\partial s_{\text {open }}} L^{v, \text { for }}\right|+\left|\frac{\partial \text { share }}{\partial s_{x, f o r}} \frac{\partial s_{x, \text { for }}}{\partial \tau}\right|$.

This implies that the number of formal jobs eliminated at the $s_{\text {open }}$ curve are much larger than the number of informal jobs lost along the $s_{\text {open }}$ and the $s_{x, \text { for }}$ curves, and the number of formal jobs generated along the $s_{x, f o r}$ curve. The intuition of condition (S2) is the opposite of that of condition 
(S1). Now, we need to have the partial derivative of $\Psi$ with respect to productivity decreasing at a faster rate than the firm-level employment. Moreover, this descent has to be very steep so that, together with sufficient condition (S3) and Lemma 3, the change in the number of formal workers employed in firms lying on $s_{x, f o r}$ is smaller than the change in the number of formal workers lying on $s_{\text {open }}$. Furthermore, such change along $s_{\text {open }}$ has to be larger than the $L^{v, f o r}$ change along $s_{x, f o r}$ plus the total change in $L^{v, i n f}$. That is why condition (S3) is important, by ensuring that the initial share of informal workers is small, the change in $L^{v, i n f}$ will also be small.

Proposition 3. The effect of a reduction in the Foreign import tariff on the share of informal workers in total industry employment is ambiguous. If sufficient condition (S1) holds, then a reduction in $\tau^{*}$ will decrease the share of informal workers in total industry employment.

Proof. In comparison with Proposition 2, the derivative of the share of informal of informal workers has an additional term which accounts for the change in formal employment by current exporters.

$$
\frac{d \text { share }}{d \tau^{*}}=\frac{\partial \text { share }}{\partial s_{\text {open }}} \frac{\text { partials }_{\text {open }}}{\partial \tau^{*}}+\frac{\partial \text { share }}{\partial s_{x, \text { for }}} \frac{\partial s_{x, \text { for }}}{\partial \tau^{*}}+\frac{\partial \text { share }}{\partial \tau^{*}}
$$

A decrease in the Foreign import tariff leads to an expansion of formal employment by current exporters, hence $\partial$ share $/ \partial \tau^{*}>0$. Given that $\partial s_{\text {open }} / \partial \tau^{*}<0$ and $\partial s_{x, \text { for }} / \partial \tau^{*}>0$, the ambiguity is similar to that which was discussed for Proposition 2. So, Lemma 2 can be applied to arrive at $\left.\mid \partial s_{x, \text { for }} / \partial \tau^{*}\right)|>| \partial s_{\text {open }} / \tau^{*} \mid$. Then, the rest of the proof is similar to that for Proposition 2 case a.

Notice that conditions (S2) and (S3) are not sufficient to generate the opposite prediction, as in Proposition 2 case $\mathrm{b}$, due to the additional term $\partial$ share $/ \partial \tau^{*}$.

Proposition 4. The effect of a reduction in the Home import tariff on the industry-level average formal wage is ambiguous. If the sufficient conditions (S4) and (S5) hold, where condition (S4) $\partial \Psi / \partial W<-\sigma T /(T W+\theta)$ and condition $(S 5)$ is $\partial \Psi / \partial \varphi<0$, a reduction in the Home import tariff will decrease the industry-level average formal wage.

Proof. Notice that the derivative of the average formal wage with respect to Home import tariff is given by

$$
\frac{d \bar{w}^{\text {for }}}{d \tau}=\left(\frac{\partial \bar{w}^{\text {for }}}{\partial s_{\text {open }}} \frac{\partial s_{\text {open }}}{\partial \tau}+\frac{\partial \bar{w}^{\text {for }}}{\partial s_{x, \text { for }}} \frac{\partial s_{x, \text { for }}}{\partial \tau}\right) \frac{d W_{1}}{d \tau}
$$


From Lemma $1, d W_{1} / d \tau>0$. So, the sign of $d \bar{w}^{\text {for }} / d \tau$ is given by the sign of the term inside the parentheses, which can be determined by comparing the average formal wage with the average wage of the formal firms lying on the curve $s_{\text {open }}$ and $s_{x, \text { for }}$ where the derivative is evaluated. The sign of the term inside the parentheses will be positive if the average formal wage of the firms along $s_{\text {open }}$ is larger than $\bar{w}^{\text {for }}$ and if the average formal wage of the firms along $s_{x, f o r}$ is smaller than $\bar{w}^{\text {for }}$. This is ensured by Lemma 2 and conditions (S4) and (S5). In particular, conditions (S4)-(S5) guarantee that as $\varphi$ and $W$ increase, the joint probability still decreases faster than the employment level. As a result, the average formal wage along $s_{\text {open }}$ is larger than the average formal wage along $s_{x, f o r}$.

Proposition 5. The effect of a reduction in the Foreign import tariff on the industry-level average formal wage is ambiguous. If conditions (S4) and (S5) hold, a reduction in the Foreign import tariff will increase the industry-level average formal wage.

Proof. In comparison with Proposition 4, the derivative of the average formal wage has an additional term that accounts for the change in the average formal wage with respect to changes in the employment level of current exporters, $\partial \bar{w}^{f o r} / \partial \tau^{*}$.

$$
\frac{d \bar{w}^{\text {for }}}{d \tau^{*}}=\left(\frac{\partial \bar{w}^{\text {for }}}{\partial s_{\text {open }}} \frac{\partial s_{\text {open }}}{\partial \tau^{*}}+\frac{\partial \bar{w}^{\text {for }}}{\partial s_{x, \text { for }}} \frac{\partial s_{x, \text { for }}}{\partial \tau^{*}}+\frac{\partial \bar{w}^{\text {for }}}{\partial \tau^{*}}\right) \frac{d W_{1}}{d \tau^{*}}
$$

The sign of $d \bar{w}^{\text {for }} / d \tau^{*}$ is given by the opposite sign of the term inside the parentheses, since Lemma 1 implies $d W_{1} / d \tau^{*}<0$. Thus, as shown in equation (26), the term inside the curly brackets must be positive.

$$
\begin{aligned}
\operatorname{sgn}\left[\frac{d \bar{w}^{f o r}}{d \tau^{*}}\right]=-\operatorname{sgn}\left[\frac{\partial t w p^{f o r}}{\partial \tau^{*}}-\bar{w}^{\text {for }} \frac{\partial L^{v, f o r}}{\partial \tau^{*}}\right. & +\frac{\partial t w p^{f o r}}{\partial s_{\text {open }}} \frac{\partial s_{\text {open }}}{\partial \tau^{*}}-\bar{w}^{\text {for }} \frac{\partial L^{v, \text { for }}}{\partial s_{\text {open }}} \frac{\partial s_{\text {open }}}{\partial \tau^{*}} \\
& \left.+\frac{\partial t w p^{\text {for }}}{\partial s_{x, f o r}} \frac{\partial s_{x, \text { for }}}{\partial \tau^{*}}-\bar{w}^{\text {for }} \frac{\partial L^{v, \text { for }}}{\partial s_{x, \text { for }}} \frac{\partial s_{x, f o r}}{\partial \tau^{*}}\right]
\end{aligned}
$$

The reasoning behind the proof here is similar to that used in Proposition 4. As in Proposition 4, conditions (S4) and (S5) and Lemma 2 ensure that the resulting sign of the last four terms inside the curly brackets is positive. Here, we also need to have a positive sign for the first two 
terms. Given that $\partial t w p^{\text {for }} / \partial \tau^{*}<0$ and $\partial L^{V, \text { for }} / \partial \tau^{*}<0$, the first two terms in equation (26) will be positive if the average formal wage of the exporters is smaller than the overall average formal wage. From Proposition 4, this happens whenever conditions (S4) and (S5) hold. Thus, $d \bar{w}^{\text {for }} / d \tau^{*}<0$.

\section{A.3 Data description}

\section{A.3.1 Worker Data}

The industry aggregation level used is dictated by the PNAD industry classification, which originally consisted of 16 manufacturing industries. The petroleum refining and petrochemicals industry was excluded from the analysis because it is composed of government-owned firms that employ a small number of workers, and by definition always complies with tax regulations.

If a worker had multiple jobs, only the information about the main job was used. The hourly wage was calculated as the monthly wage divided by four times the hours worked per week. The share of informal workers in industry $j$ in year $t$ consists of the average of the informality indicator weighted by the sample weights provided by the PNAD and the census.

\section{A.3.2 Tariff Data}

The 1989-2001 Brazilian import tariff and the effective rate of protection (ERP) data come from Kume et al. (2003), and these series were originally aggregated by industry value-added at IBGE's Nível 50 industry classification. Using industry value added as weights, I further aggregated the data into the 15 manufacturing industries shown in Table 3.

The data on Argentina's import tariffs on Brazilian goods for the 1991-2001 period come from Freund et al. (2008) and are at the 4-digit ISIC level. The 3-digit ISIC level data for 1990 come from Liftschitz (1991). I used 1990 data for 1989 because there are no data available for this year. Then, I aggregated the data into my 15-industry classification by simple average. The U.S. data come from Feenstra et al. (2002) at Standard International Trade Classification (SITC). The import tariff on Brazilian goods is calculated as the ratio between import duties and customs value, which I further aggregated to my 15-industry classification using simple average.

For the remaining countries, I used the 1974-2006 Trade, Production, and Protection (TPP) 
data at the 3-digit ISIC level from Nicita and Olarreaga (2006). Each trade partner's import tariff is the simple average tariff rate in percentage points that must be paid for the good at the border of the importing country by a most favored nation (tar_savg_mfn). I aggregated each partner's export tariff data by simple average into my 15-industry classification. There are no data for China for the 1989-1991 period, so for these years I assumed the same tariff level as was in effect in 1992. 